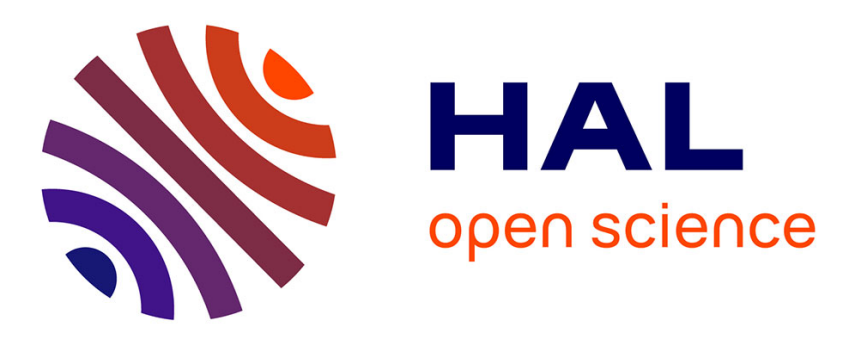

\title{
Are Condorcet procedures so bad according to the reinforcement axiom?
}

Sébastien Courtin, Boniface Mbih, Issofa Moyouwou

\section{To cite this version:}

Sébastien Courtin, Boniface Mbih, Issofa Moyouwou. Are Condorcet procedures so bad according to the reinforcement axiom?. Social Choice and Welfare, 2014, 42 (4), pp.927-940. 10.1007/s00355-0130758-7 . hal-00914870

\author{
HAL Id: hal-00914870 \\ https://hal.science/hal-00914870
}

Submitted on 6 Dec 2013

HAL is a multi-disciplinary open access archive for the deposit and dissemination of scientific research documents, whether they are published or not. The documents may come from teaching and research institutions in France or abroad, or from public or private research centers.
L'archive ouverte pluridisciplinaire HAL, est destinée au dépôt et à la diffusion de documents scientifiques de niveau recherche, publiés ou non, émanant des établissements d'enseignement et de recherche français ou étrangers, des laboratoires publics ou privés. 


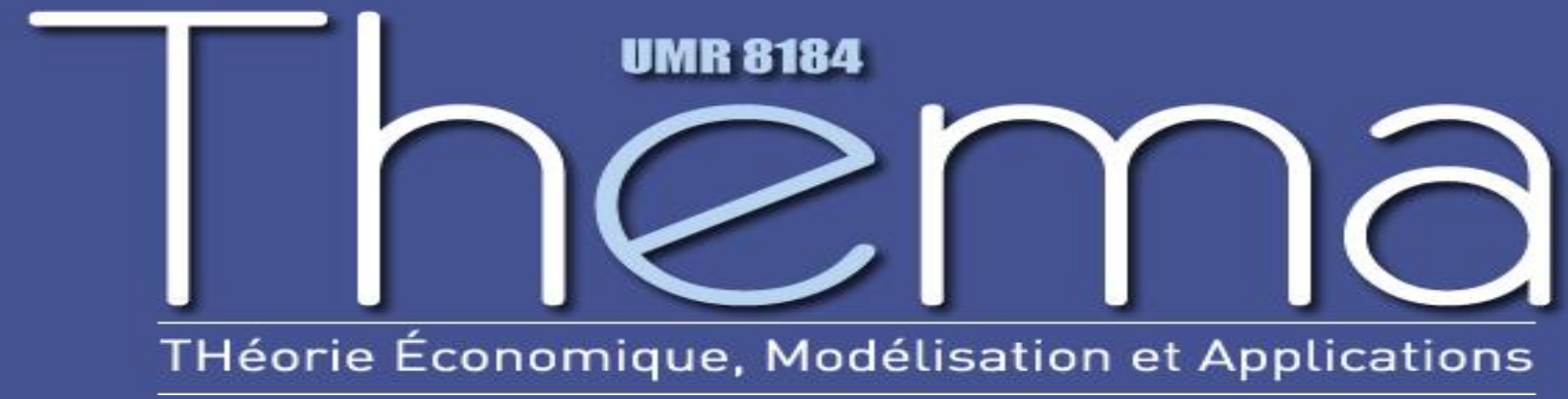

Thema Working Paper $\mathrm{n}^{\circ}$ 2012-37

Université de Cergy Pontoise, France

Are Condorcet procedures so bad according to the reinforcement axiom?

Sébastien Courtin

Boniface Mbih

Issofa Moyouwou

September, 2012 


\title{
Are Condorcet procedures so bad according to the reinforcement axiom?
}

\author{
Sébastien Courtin* $\quad$ Boniface Mbih $^{\dagger} \quad$ Issofa Moyouwou $\ddagger$
}

September 2012

\begin{abstract}
A Condorcet social choice procedure elects the candidate that beats every other candidate under simple majority when such a candidate exists. The reinforcement axiom roughly states that given two groups of individuals, if these two groups select the same alternative, then this alternative must also be selected by their union. Condorcet social choice procedures are known to violate this axiom. Our goal in this paper is to put this important voting theory result into perspective. We then proceed by evaluating how frequently this phenomenon is susceptible to occur.
\end{abstract}

Keywords Condorcet procedures $\bullet$ Reinforcement axiom $\bullet$ Likelihood $\bullet$ Impartial culture Impartial anonymous culture

\section{JEL Classification D71}

\footnotetext{
${ }^{*}$ Corresponding author. University of Cergy-Pontoise, THEMA, UMR CNRS 8184, France. Email: sebastien.courtin@u-cergy.fr

${ }^{\dagger}$ Université of Caen Basse-Normandie, CREM, UMR CNRS 6211, Caen, France. Email: boniface.mbih@unicaen.fr

†University of Yaounde I, Department of Mathematics, Advanced Teachers’ Training College, Cameroon. Email: imoyouwou2@yahoo.fr
} 


\section{Introduction}

Most of the literature on voting theory is concerned with the theoretical debate between Condorcet consistent social choice methods on the one hand, and positional (or scoring) systems - voting $\grave{a}$ la Borda - on the other hand. There are several arguments in favor of either type of procedures, discussed in an abundant literature (see Nurmi 1987 and 1999, and Saari 2006 among others).

One of the strongest arguments in favor of Borda's approach is the reinforcement axiom $(R A)$. The notion of reinforcement was first introduced by Smith (1973), under the name of separability. The intuition is as follows: if two different blocks of individuals rank an alternative at least as high as some other alternative, then so does the combination of the blocks with regard to these two alternatives.

In the same way - and indeed at the same period - Young $(1974,1975 \mathrm{a})$ proposes a variant of the notion of separability, which he calls consistency. Following this idea, if two disjoint groups of individuals separately select two non-disjoint subsets of alternatives, then the union of these groups should exactly select the intersection of the two subsets. In fact, the difference between the two contributions lies in the type of social choice mechanisms studied: Young is concerned with social choice correspondences (selecting possibly more than a single alternative), while Smith is interested in aggregation functions (selecting a social ranking of alternatives from preferences reported by individual voters).

And finally, in the special context of social choice functions (correspondences selecting a unique outcome), which we consider in this paper, Moulin (1988) introduces the phrase reinforcement axiom $(R A)$.

In order to illustrate this phenomenon, consider the following situation, concerning two french districts. For several years now, there has been a project of reunification of two northwestern districts, the "Basse-Normandie" (almost 1500000 inhabitants with Caen as the capital) and the "Haute-Normandie" (almost 1800000 inhabitants and Rouen as the capital). Almost all the inhabitants of these two districts agree with this project, but they disagree on the new capital. They will have to choose between three cities, Caen, Rouen and Le Havre (which is another big city in Haute-Normandie). Given the importance of this decision, we assume that the chosen project must be firstly accepted by each of the two districts separately; and secondly, if both districts choose the same city, then there is a further step, in which all inhabitants of both districts will be asked to cast their votes. ${ }^{1}$

Now, after the first step of the process, assume that the inhabitants in Basse-Normandie and in Haute-Normandie have chosen Caen. Further, assume that with the same individual preferences Le Havre is the winner of the second step. Then Caen wins in each of the two districts separetely, but not in their union. This is typically an example of violation of the reinforcement axiom.

The main results concerning the violation of $R A$ are summarized in Young's theorem (1975a). According to this theorem, all simple positional voting procedures satisfy $R A$, while on the contrary there is no Condorcet social choice procedure satisfying that axiom.

There is no doubt about the importance of this proposition, since it provides a clear axiomatic boundary between Borda's and Condorcet's approaches of social choice mechanisms. In this paper, we examine the violation of $R A$ under the most widely studied Condorcet procedures (see Fishburn 1977 or Rasch 1995, among others). Our goal is to examine precise conditions at which violations

\footnotetext{
${ }^{1}$ This process is usual in France, especially for a constitutional revision.
} 
of $R A$ are susceptible to arise under these rules. We give, among other statements, conditions on the minimum number of voters at which the phenomenon arises.

Besides, this normative contribution is completed by a measure of the quantitative significance of the violation of $R A$. Indeed, if the likelihood of such violation of $R A$ is negligible, then one need not be unduly worried about the existence of the possibility as such. In fact, although these rules violate $R A$, this should not be a serious ground for rejecting them or to discriminate in favor of Borda's approach (see Courtin et al. 2010 for a study on the violation of $R A$ under sequential positional procedures).

The remainder of this work is organized as follows: Section 2 is a presentation of Condorcet social choice functions with definitions and some preliminary results about these rules. Section 3 provides some general results on the behavior of Condorcet's rules vis-à-vis the reinforcement axiom. Then, Section 4 studies the conditions at which a profile may violate the axiom, and provides the corresponding frequencies. Finally, Section 5 concludes the paper.

\section{Condorcet social choice functions}

In this section, we begin with formal definitions of Condorcet rules and we investigate some relationships between them.

\subsection{Notations and definitions}

Consider a finite set $N$ of $n$ individuals or voters, with $n \geq 2$ and a finite set $A$ of $m$ alternatives, with $m \geq 3$. Suppose two disjoint groups (or constituencies) $T_{1}$ and $T_{2}$ of individuals, with $T_{1} \cup T_{2}=N$. Let $2^{A}$ be the set of nonempty subsets of $A$. Assume that the preference relation $R^{i}$ of individual $i, i \in N$, is a complete, antisymmetric and transitive binary relation (or simply a linear order) on $A$ and let $L=\left\{R_{k}: 1 \leq k \leq m\right.$ ! $\}$ be the set of all linear orders on $A$.

A profile on $A$ is an $n$-tuple $R^{N}=\left(R^{i}\right)_{i \in N}$ of individual preference relations, one for each individual. The set of all profiles on $N$ will be denoted by $L^{N}$. Similarly profiles on $T_{1}$ and $T_{2}$ will be denoted $R^{T_{1}}$ and $R^{T_{2}}$, respectively.

Definition 1. Let $N$ be the nonempty set of voters. Then

i) A social choice function $(S C F)$ is a mapping that associates a single alternative with any profile over a nonempty subset of $N$.

ii) A social choice correspondence $(S C C)$ is a mapping that associates a nonempty subset of alternatives with any profile over a nonempty subset of $N$.

Note that $F\left(R^{N}\right)$ and $C\left(R^{N}\right)$, given an $S C F F$ and an $S C C C$, are the images determined respectively by $F$ and $C$ for a set of alternatives $A$ and a profile $R^{N}$ on that set.

Given a profile $R^{N}$ and alternatives $x, y \in A$, we denote by $n\left(x, y, R^{N}\right)$ the number of individuals in $R^{N}$ who prefer $x$ to $y$ (or simply $n(x, y)$ when there is no ambiguity). Hence $n(x, y)+n(y, x)=n$. Then the simple majority relation $M$ on $A$ determined by profile $R^{N}$ is defined by

$$
x M y \text { iff } n(x, y)>n(y, x)
$$

There is a tie between $x$ and $y$ under simple majority if 


$$
n(x, y)=n(y, x)
$$

Definition 2. An $S C F F$ is a Condorcet $S C F$ if and only if it satisfies the Condorcet Principle, that is for all profile $R^{N}$ and all $x \in A, x M y$ for all $y \in A$ implies $F\left(R^{N}\right)=x$.

We now define the rules under study in this paper. In order to do this, we follow Fishburn's 1977 terminology ${ }^{2}$. For each $S C C\left(C_{j}\right)$, we obtain an $S C F\left(F_{j}\right)$ by breaking ties in favor of the alternative coming first in the lexicographic order. For example, if two alternatives $x$ and $y$ are tied, then $F\left(R^{N}\right)=x$.

$C_{1}$. Black's function: $C_{1}\left(R^{N}\right)=\{x$ if $y M x$ for no $y \in A\}$. Otherwise $C_{1}\left(R^{N}\right)=\left\{x\right.$ if $b\left(x, R^{N}\right)$ $\geq b\left(y, R^{N}\right)$ for all $\left.\mathrm{y} \in A\right\}$, where $b\left(x, R^{N}\right)=\sum_{y \in A} n(x, y)$ is the Borda score of $x$ given $R^{N}$.

According to this function, if no candidate beats or ties every other candidate on the basis of simple majority, then the SCF should be determined by the Borda scores.

$C_{2}$. Copeland's function: $C_{2}\left(R^{N}\right)=\left\{x \in A: c\left(x, R^{N}\right) \geq c\left(y, R^{N}\right)\right.$ for all $\left.y \in A\right\}$, where $c\left(x, R^{N}\right)$ $=|y \in A: x M y|-|y \in A: y M x|$ is the Copeland score of $x$, that is the number of alternatives beaten by $x$ minus the number of alternatives that beat $x$.

$C_{3}$. Dodgson's function: $C_{3}\left(R^{N}\right)=\left\{x \in A: d\left(x, R^{N}\right) \leq d\left(y, R^{N}\right)\right.$ for all $\left.y \in A\right\}$, where $d\left(x, R^{N}\right)$ is the number of binary preference reversals needed in $R^{N}$ to make $x$ tie or beat every other candidate in $A$ on the basis of simple majority. A reversal occurs when $x R^{i} y$ is changed into $y R^{i} x$. In other words $d\left(x, R^{N}\right)$ is a measure of how little $R^{N}$ needs to be changed to make $x$ tie or beat every other candidate.

$C_{4}$. Young's function: $C_{4}\left(R^{N}\right)=\left\{x \in A: e\left(x, R^{N}\right) \geq e\left(y, R^{N}\right)\right.$ for all $\left.y \in A\right\}$, where $e\left(x, R^{N}\right)$ is the number of voters in the largest sublist from $R^{N}$ for which $x$ ties or beats every other candidate in $A$ on the basis of simple majority with respect to this sublist. If there is no such sublist then $e\left(x, R^{N}\right)=0$. This means that $E\left(x, R^{N}\right)=n-e\left(x, R^{N}\right)$ gives the fewest number of voters that must be deleted from $R^{N}$ for $x$ to tie or beat every other candidate.

In contrast to Dodgson's function, Young's function deletes voters rather than reversing preferences to obtain a majority winner.

$C_{5}$. Condorcet's function : $C_{5}\left(R^{N}\right)=\left\{x \in A: f\left(x, R^{N}\right) \geq f\left(y, R^{N}\right)\right.$ for all $\left.y \in A\right\}$, where $f\left(x, R^{N}\right)=\min _{y \in A \backslash x} n(x, y)$. That is $f\left(x, R^{N}\right)$ measures the worst that $x$ does against any other candidate.

Condorcet's function selects the alternative with the largest minimum support in all pairwise comparisons. It sometimes goes under the names of minimax rule (Young 1975b) or maximin rule (see for example Nurmi 2002).

$C_{6}$. Kemeny's function: Given $R^{N}$ with $A=\left\{a_{1}, a_{2}, \ldots, a_{m}\right\}$, let $L^{*}$ be a subset of linear orders $R_{k}$ on $A$ that maximize $S\left(R_{k}\right)=\sum_{i \neq j} n\left(a_{i}, a_{j}\right) K\left(a_{i}, a_{j}\right)$, where $K\left(a_{i}, a_{j}\right)=1$ if $a_{i} R_{k} a_{j}$ and $K\left(a_{i}, a_{j}\right)=0$ otherwise. Then $C_{6}\left(R^{N}\right)=\left\{x \in A\right.$ : there is an $R_{k} \in L^{*}$ such that $x R_{k} y$ for all $y \in$ $A \backslash\{x\}\}$. That is $C_{6}\left(R^{N}\right)=\left\{x \in A: k\left(x, R^{N}\right) \geq k\left(y, R^{N}\right)\right.$ for all $\left.y \in A\right\}$ where $k\left(x, R^{N}\right)=$ $\max \left\{S\left(R_{k}\right): R_{k} \in L\right.$ and $x R_{k} y$ for all $\left.y \in A\right\}$ (or simply $k(x)$ when there is no ambiguity).

Kemeny's function can be viewed as a measure of the closeness of individual preferences in some profile with the linear order $R_{k}$ derived from that profile as indicated above.

$C_{7}$. Schwartz's function: $C_{7}\left(R^{N}\right)=\{x \in A: y S x$ for no $y \in A\}$, where $x S y$ iff there are $x_{1}=$ $x, x_{2}, \ldots, x_{k}=y$ in $A$ such that $x_{1} M x_{2}, x_{2} M x_{3}, \ldots, x_{k-1} M x_{k}$, and there are no $z_{1}=y, z_{2}, \ldots, z_{j}=x$ in $A$ such that $z_{1} M z_{2}, z_{2} M z_{3}, \ldots, z_{j-1} M z_{j}$.

${ }^{2} C_{1}$ was introduced by Black (1958); $C_{2}$ by Copeland (1951); $C_{3}$ by Dodgson (1876); $C_{4}$ and $C_{5}$ by Young (1975b); $C_{6}$ by Kemeny (1959) and Levenglick (1975); $C_{7}$ by Schwartz (1972); and $C_{8}$ by Fishburn (1970). 
Schwartz's function elects the alternative that is beaten by no other alternative according to the majority election, directly or indirectly.

$C_{8}$. Fishburn's function: $C_{8}\left(R^{N}\right)=\{x \in A: y F x$ for no $y \in A\}$, where $x F y$ iff for every $a \in A$, $a M x \Rightarrow a M y$; and there is a $w \in A$ such that $w M y$ and not $(w M x)$.

Fishburn's function is based on the notion that if every candidate that beats $x$ also beats $y$ under simple majority, and if there exists some candidate that beats $y$ but not $x$, then $x$ is "better than" $y$ under simple majority comparisons.

We now introduce another Condorcet $S C F$, not defined by Fishburn (1977), the Amendment's function (see Farquharson 1969) denoted $C_{9}$.

$C_{9}$. Amendment function: With $A=\left\{a_{1}, a_{2}, \ldots, a_{m}\right\}$, the outcome of $C_{9}$ is the alternative $C_{9}\left(R^{N}\right)$ defined as follows:

i) Let $C_{9}\left(R^{N}\right)_{1}=a_{1}$.

ii) For any $2 \leq j \leq m$, the winner $C_{9}\left(R^{N}\right)_{j}$ of the majority pairwise contest between $C_{9}\left(R^{N}\right)_{j-1}$ and $a_{j}$ is defined by $C_{9}\left(R^{N}\right)_{j}=\left\{\begin{array}{ll}a_{j} & \text { if } a_{j} M C_{9}\left(R^{N}\right)_{j-1} . \\ C_{9}\left(R^{N}\right)_{j-1} & \text { otherwise }\end{array}\right.$.

iii) $C_{9}\left(R^{N}\right)=C_{9}\left(R^{N}\right)_{m}$, the winner of the last majority contest against $a_{m}$.

The intuition of this procedure is as follows: any motion $C_{9}\left(R^{N}\right)_{j-1}$ is saved as long as a strict majority does not reject it in favor of some other motion $a_{j}$ given the agenda $A=\left\{a_{1}, a_{2}, \ldots, a_{m}\right\}$.

\subsection{The special case of three alternatives}

Some additional notations will be necessary to present some results in the three-alternative case. With $A=\left\{a_{1}, a_{2}, a_{3}\right\}$, the six possible linear orders on $A$ are: $R_{1}: a_{1} a_{2} a_{3}, R_{2}: a_{1} a_{3} a_{2}, R_{3}: a_{2} a_{1} a_{3}$, $R_{4}: a_{2} a_{3} a_{1}, R_{5}: a_{3} a_{1} a_{2}, R_{6}: a_{3} a_{2} a_{1}$. And in the sequel, $n_{k}$ will be the total number of individuals in $N$ with preference relation $R_{k}$.

Further, in the three-alternative case, a Condorcet cycle arises when every alternative is beaten (on the basis of simple majority) by only one other alternative. Two possible cycles can arise:

1. Condorcet cycle 1: $a_{2} M a_{1}, a_{1} M a_{3}$ and $a_{3} M a_{2}$

2. Condorcet cycle 2: $a_{1} M a_{2}, a_{2} M a_{3}$ and $a_{3} M a_{1}$.

We shall distinguish two cases : (i) when there is a Condorcet cycle, and (ii) when there is none.

\subsubsection{Condorcet Cycle}

We first show how to compute the score of each alternative $a_{j}, a_{k}, a_{l} \in\left\{a_{1}, a_{2}, a_{3}\right\}$, when there is a Condorcet cycle, according to Dodgson's, Young's, Condorcet's and Kemeny's procedures.

We begin with Dodgson.

\section{Dodgson's procedure}

Proposition 1. If $a_{k} M a_{j}$ in some profile $R^{N}$, then the minimum number of binary preference reversals needed in $R^{N}$ to make $a_{j}$ tie or beat $a_{k}$ is $\left\lfloor\frac{n+1}{2}\right\rfloor-n\left(a_{j}, a_{k}\right)$, where $\lfloor x\rfloor$ is the floor function of $x$. 
Proof. Consider two profiles $R^{N}$ and $\bar{R}^{N}$ such that $a_{k} M a_{j}$ in $R^{N}$ but not in $\bar{R}^{N}$. Then $n\left(a_{j}, a_{k}, R^{N}\right)<$ $\frac{n}{2}$ and $n\left(a_{j}, a_{k}, \bar{R}^{N}\right) \geq \frac{n}{2}$. Let $d\left(a_{j}, a_{k}\right)$ be the number of binary preference reversals $a_{k}$ to $a_{j}$ between $R^{N}$ and $\bar{R}^{N}$. Then $n\left(a_{j}, a_{k}, \bar{R}^{N}\right)=n\left(a_{j}, a_{k}, R^{N}\right)+d\left(a_{j}, a_{k}\right) \geq \frac{n}{2}$. Hence

$$
d\left(a_{j}, a_{k}\right) \geq \frac{n}{2}-n\left(a_{j}, a_{k}, R^{N}\right)
$$

Since $d\left(a_{j}, a_{k}\right)$ is the minimum number of reversals needed to have $a_{j} M a_{k}$ in $\bar{R}^{N}$, then $n\left(a_{j}, a_{k}, R^{N}\right)+$ $d\left(a_{j}, a_{k}\right)-1<\frac{n}{2}$, which can be rewritten as $2 n\left(a_{j}, a_{k}, R^{N}\right)+2 d\left(a_{j}, a_{k}\right)-2<n$, and since every term of this inequality is an integer, this can also be rewritten as $2 n\left(a_{j}, a_{k}, R^{N}\right)+2 d\left(a_{j}, a_{k}\right)-1 \leq n$, which gives

$$
d\left(a_{j}, a_{k}\right) \leq \frac{n+1}{2}-n\left(a_{j}, a_{k}, R^{N}\right)
$$

It then follows from (1) and (2) that $\frac{n}{2}-n\left(a_{j}, a_{k}, R^{N}\right) \leq d\left(a_{j}, a_{k}\right) \leq \frac{n+1}{2}-n\left(a_{j}, a_{k}, R^{N}\right)$, and finally, $d\left(a_{j}, a_{k}\right)=\left\lfloor\frac{n+1}{2}\right\rfloor-n\left(a_{j}, a_{k}\right)$, which completes the proof.

Proposition 2. If there exists a Condorcet cycle at some profile $R^{N}$, then the Dodgson score of an alternative $a_{j}$ is given by $d\left(a_{j}, R^{N}\right)=d\left(a_{j}, a_{k}\right)=\left\lfloor\frac{n+1}{2}\right\rfloor-n\left(a_{j}, a_{k}\right)$, where $a_{k}$ is the unique alternative such that $a_{k} M a_{j}$.

Proof. Consider some profile $R^{N}$ and some alternative $a_{j}$ and suppose there is a Condorcet cycle; then $a_{j}$ is beaten by only one other alternative, say $a_{k}$. Since $a_{j}$ is beaten only by $a_{k}$, the number of binary preference reversals needed in $R^{N}$ to make $a_{j}$ tie or beat every other candidate in $A$ on the basis of simple majority, $d\left(a_{j}, R^{N}\right)$, is equal to the number of binary preference reversals needed in $R^{N}$ to make $a_{j}$ tie or beat $a_{k}$, that is $d\left(a_{j}, a_{k}\right)=\left\lfloor\frac{n+1}{2}\right\rfloor-n\left(a_{j}, a_{k}\right)$.

As a consequence, we have the following Dodgson scores for the two Condorcet cycles, with $A=\left\{a_{1}, a_{2}, a_{3}\right\}$ :

$$
\begin{aligned}
& \text { Cycle 1: } a_{2} M a_{1}, a_{1} M a_{3} \text { and } a_{3} M a_{2} \\
& \hline d\left(a_{1}, R^{N}\right)=\left\lfloor\frac{n+1}{2}\right\rfloor-n\left(a_{1}, a_{2}\right)=\left\lfloor\frac{n+1}{2}\right\rfloor-\left(n_{1}+n_{2}+n_{5}\right) \\
& d\left(a_{2}, R^{N}\right)=\left\lfloor\frac{n+1}{2}\right\rfloor-n\left(a_{2}, a_{3}\right)=\left\lfloor\frac{n+1}{2}\right\rfloor-\left(n_{1}+n_{3}+n_{4}\right) \\
& d\left(a_{3}, R^{N}\right)=\left\lfloor\frac{n+1}{2}\right\rfloor-n\left(a_{3}, a_{1}\right)=\left\lfloor\frac{n+1}{2}\right\rfloor-\left(n_{4}+n_{5}+n_{6}\right)
\end{aligned}
$$

and

$$
\begin{aligned}
& \text { Cycle } 2: a_{1} M a_{2}, a_{2} M a_{3} \text { and } a_{3} M a_{1} \\
& d\left(a_{1}, R^{N}\right)=\left\lfloor\frac{n+1}{2}\right\rfloor-n\left(a_{1}, a_{3}\right)=\left\lfloor\frac{n+1}{2}\right\rfloor-\left(n_{1}+n_{2}+n_{3}\right) \\
& d\left(a_{2}, R^{N}\right)=\left\lfloor\frac{n+1}{2}\right\rfloor-n\left(a_{2}, a_{1}\right)=\left\lfloor\frac{n+1}{2}\right\rfloor-\left(n_{3}+n_{4}+n_{6}\right) \\
& d\left(a_{3}, R^{N}\right)=\left\lfloor\frac{n+1}{2}\right\rfloor-n\left(a_{3}, a_{2}\right)=\left\lfloor\frac{n+1}{2}\right\rfloor-\left(n_{2}+n_{5}+n_{6}\right)
\end{aligned}
$$




\section{Young's procedure}

Proposition 3. If for each alternative $a_{j} \in A$ there exists only one $a_{k} \in A$ such that $a_{k} M a_{j}$ in some profile $R^{N}$, then $E\left(a_{j}, R^{N}\right)=n-2 n\left(a_{j}, a_{k}\right)$.

Proof. Let $A=\left\{a_{j}, a_{k}, a_{l}\right\}$ and consider a profile $R^{N}$ such that $a_{k} M a_{j}$ in $R^{N}$ and not $\left(a_{k} M a_{j}\right)$ for some profile $R^{N^{\prime}}$ obtained from $R^{N}$ by removing some voters that strictly prefer $a_{k}$ to $a_{j}$.

Suppose that $R^{N^{\prime}}$ is obtained using a minimal number of cancellations $E\left(a_{j}, R^{N}\right)$. Let us prove that $E\left(a_{j}, R^{N}\right)=n-2 n\left(a_{j}, a_{k}, R^{N}\right)$.

A) We first prove that $E\left(a_{j}, R^{N}\right) \geq n-2\left(a_{j}, a_{k}, R^{N}\right)$.

By hypothesis on $R^{N}$ and $R^{N^{\prime}}$, it follows that

$$
n\left(a_{j}, a_{k}, R^{N}\right)<\frac{n}{2}, n\left(a_{j}, a_{k}, R^{N^{\prime}}\right) \geq \frac{n^{\prime}}{2} \text { and } n\left(a_{j}, a_{k}, R^{N^{\prime}}\right)=n\left(a_{j}, a_{k}, R^{N}\right)
$$

with $n^{\prime}=\left|N^{\prime}\right|$. Therefore

$$
\frac{n^{\prime}}{2} \leq n\left(a_{j}, a_{k}, R^{N}\right)<\frac{n}{2}
$$

Since $E\left(a_{j}, R^{N}\right)=n-n^{\prime}$,

$$
\frac{n-E\left(a_{j}, R^{N}\right)}{2} \leq n\left(a_{j}, a_{k}, R^{N}\right)<\frac{n}{2}
$$

Therefore

$$
E\left(a_{j}, R^{N}\right) \geq n-2 n\left(a_{j}, a_{k}, R^{N}\right)>0(1)
$$

B) We now prove that $E\left(a_{j}, R^{N}\right) \leq n-2 n\left(a_{j}, a_{k}, R^{N}\right)$.

Note that $n\left(a_{k}, a_{j}, R^{N}\right)+n\left(a_{j}, a_{k}, R^{N}\right)=n$. Then relation (1) can be rewritten as follows:

$$
E\left(a_{j}, R^{N}\right) \geq n\left(a_{k}, a_{j}, R^{N}\right)-n\left(a_{j}, a_{k}, R^{N}\right)>0
$$

Consider $q=n\left(a_{k}, a_{j}, R^{N}\right)-n\left(a_{j}, a_{k}, R^{N}\right)$. Two cases arise.

a) $q \leq n\left(a_{k} a_{l} a_{j}, R^{N}\right)+n\left(a_{l} a_{k} a_{j}, R^{N}\right)$ where $n\left(a_{u} a_{v} a_{w}, R^{N}\right)$ is the total number of voters with preference relation of type $a_{u} a_{v} a_{w}$.

In that case by deleting exactly $q$ voters in $R^{N}$ with preference relation $a_{k} a_{l} a_{j}$ or $a_{l} a_{k} a_{j}$, we have in $R^{N^{\prime}}$ :

$$
n\left(a_{j}, a_{k}, R^{N^{\prime}}\right)-n\left(a_{k}, a_{j}, R^{N^{\prime}}\right)=n\left(a_{j}, a_{k}, R^{N}\right)-\left(n\left(a_{k}, a_{j}, R^{N}\right)-q\right)=0
$$

Then $n\left(a_{j}, a_{k}, R^{N^{\prime}}\right)=n\left(a_{k}, a_{j}, R^{N^{\prime}}\right)(2)$.

Moreover deleted voters all prefer $a_{l}$ to $a_{j}$. Then,

$$
n\left(a_{j}, a_{l}, R^{N^{\prime}}\right)=n\left(a_{j}, a_{l}, R^{N}\right) \text { and } n\left(a_{l}, a_{j}, R^{N^{\prime}}\right)<n\left(a_{l}, a_{j}, R^{N}\right) .
$$

Since not $\left(a_{l} M a_{j}\right)$ holds, then

$$
n\left(a_{j}, a_{l}, R^{N}\right) \geq n\left(a_{l}, a_{j}, R^{N}\right)
$$

Therefore

$$
n\left(a_{j}, a_{l}, R^{N^{\prime}}\right) \geq n\left(a_{l}, a_{j}, R^{N}\right)>n\left(a_{l}, a_{j}, R^{N^{\prime}}\right)
$$

Hence from (2) and (3) $a_{j}$ ties $a_{k}$ and defeats $a_{l}$ in $R^{N^{\prime}}$. Thus

$$
E\left(a_{j}, R^{N}\right) \leq q=n-2 n\left(a_{j}, a_{k}, R^{N}\right)
$$


b) $q>n\left(a_{k} a_{l} a_{j}, R^{N}\right)+n\left(a_{l} a_{k} a_{j}, R^{N}\right)$. Then let $q=n\left(a_{k} a_{l} a_{j}, R^{N}\right)+n\left(a_{l} a_{k} a_{j}, R^{N}\right)+r$.

In that case we delete all the voters in $R^{N}$ with preference relation $a_{k} a_{l} a_{j}$ or $a_{l} a_{k} a_{j}$ and exactly $r$ voters with preference relation $a_{k} a_{j} a_{l}$.

At $R^{N^{\prime}}$

$$
n\left(a_{j}, a_{k}, R^{N^{\prime}}\right)-n\left(a_{k}, a_{j}, R^{N^{\prime}}\right)=0 \text { and } n\left(a_{j}, a_{k}, R^{N^{\prime}}\right)=n\left(a_{k}, a_{j}, R^{N^{\prime}}\right)(5) .
$$

Moreover, we have $n\left(a_{j}, a_{l}, R^{N^{\prime}}\right)$

$=n\left(a_{j} a_{k} a_{l}, R^{N^{\prime}}\right)+n\left(a_{j} a_{l} a_{k}, R^{N^{\prime}}\right)+n\left(a_{k} a_{j} a_{l}, R^{N^{\prime}}\right)$

$=n\left(a_{j} a_{k} a_{l}, R^{N}\right)+n\left(a_{j} a_{l} a_{k}, R^{N}\right)+n\left(a_{k} a_{j} a_{l}, R^{N}\right)-r$

$=n\left(a_{j} a_{k} a_{l}, R^{N}\right)+n\left(a_{j} a_{l} a_{k}, R^{N}\right)+n\left(a_{k} a_{j} a_{l}, R^{N}\right)-q+n\left(a_{k} a_{l} a_{j}, R^{N}\right)+n\left(a_{l} a_{k} a_{j}, R^{N}\right)$

$=2 n\left(a_{j} a_{k} a_{l}, R^{N}\right)+2 n\left(a_{j} a_{l} a_{k}, R^{N}\right)+n\left(a_{l} a_{j} a_{k}, R^{N}\right)$.

and

$n\left(a_{l}, a_{j}, R^{N^{\prime}}\right)=n\left(a_{l} a_{k} a_{j}, R^{N^{\prime}}\right)+n\left(a_{l} a_{j} a_{k}, R^{N^{\prime}}\right)+n\left(a_{k} a_{l} a_{j}, R^{N^{\prime}}\right)=n\left(a_{l} a_{j} a_{k}, R^{N}\right)$

Then

$$
n\left(a_{j}, a_{l}, R^{N^{\prime}}\right)-n\left(a_{l}, a_{j}, R^{N^{\prime}}\right)=2 n\left(a_{j} a_{k} a_{l}, R^{N}\right)+2 n\left(a_{j} a_{l} a_{k}, R^{N}\right) \geq 0(6)
$$

Hence from (5) and (6) $a_{j}$ ties $a_{k}$ and defeats $a_{l}$ in $R^{N^{\prime}}$. Therefore

$$
E\left(a_{j}, R^{N}\right) \leq q=n-2 n\left(a_{j}, a_{k}, R^{N}\right)
$$

From (1) and (7) it follows that

$$
E\left(a_{j}, R^{N}\right)=n-2 n\left(a_{j}, a_{k}, R^{N}\right)
$$

Proposition 4. If there exists a Condorcet cycle at some profile $R^{N}$, then the Young's score of an alternative $a_{j}$ is given by $e\left(a_{j}, R^{N}\right)=2 n\left(a_{j}, a_{k}\right)$ where $a_{k}$ is the unique alternative such that $a_{k} M a_{j}$.

Proof. Consider some profile $R^{N}$ and some alternative $a_{j}$ and suppose there is a Condorcet cycle; then $a_{j}$ is beaten by only one other alternative, say $a_{k}$. And by definitition $E\left(a_{j}, R^{N}\right)$ is the fewest number of voters that must be deleted from $R^{N}$ in order for $a_{j}$ to tie or beat every other candidate. By Proposition $3, E\left(a_{j}, R^{N}\right)=n-2 n\left(a_{j}, a_{k}\right)$. And since $E\left(a_{j}, R^{N}\right)=n-e\left(a_{j}, R^{N}\right)$, then $e\left(a_{j}, R^{N}\right)=n-E\left(a_{j}, R^{N}\right)=n-n+2 n\left(a_{j}, a_{k}\right)=2 n\left(a_{j}, a_{k}\right)$.

As a consequence, we have the following Young's scores for the two Condorcet cycles with $A=\left\{a_{1}, a_{2}, a_{3}\right\}$ :

$$
\begin{gathered}
\text { Cycle 1: } a_{2} M a_{1}, a_{1} M a_{3} \text { and } a_{3} M a_{2} \\
\hline e\left(a_{1}, R^{N}\right)=2 . n\left(a_{1}, a_{2}\right)=2 .\left(n_{1}+n_{2}+n_{5}\right) \\
e\left(a_{2}, R^{N}\right)=2 . n\left(a_{2}, a_{3}\right)=2 .\left(n_{1}+n_{3}+n_{4}\right) \\
e\left(a_{3}, R^{N}\right)=2 . n\left(a_{3}, a_{1}\right)=2 .\left(n_{4}+n_{5}+n_{6}\right)
\end{gathered}
$$

and 


$$
\begin{gathered}
\text { Cycle 2: } a_{1} M a_{2}, a_{2} M a_{3} \text { and } a_{3} M a_{1} \\
\hline e\left(a_{1}, R^{N}\right)=2 . n\left(a_{1}, a_{3}\right)=2 .\left(n_{1}+n_{2}+n_{3}\right) \\
e\left(a_{2}, R^{N}\right)=2 . n\left(a_{2}, a_{1}\right)=2 .\left(n_{3}+n_{4}+n_{6}\right) \\
e\left(a_{3}, R^{N}\right)=2 . n\left(a_{3}, a_{2}\right)=2 .\left(n_{2}+n_{5}+n_{6}\right)
\end{gathered}
$$

\section{Condorcet's procedure}

Proposition 5. If for each alternative $a_{j} \in A$ there exists only one $a_{k} \in A$ such that $a_{k} M a_{j}$ at some profile $R^{N}$, then the Condorcet score of $a_{j}$ is given by $f\left(a_{j}, R^{N}\right)=n\left(a_{j}, a_{k}\right)$.

Proof. By definition, $f\left(a_{j}, R^{N}\right)=\min _{x \in A \backslash a_{j}} n\left(a_{j}, x\right)$. Suppose there exists only one alternative, say $a_{k}$, such that $a_{k} M a_{j}$, in $R^{N}$. Then $n\left(a_{j}, a_{k}\right)<n\left(a_{k}, a_{j}\right)$, which means that $n\left(a_{j}, a_{k}\right)<\frac{n}{2}$. And since there is only one alternative such that $x M a_{j}$, this means that $n\left(a_{j}, a_{l}\right) \geq n\left(a_{l}, a_{j}\right) \geq \frac{n}{2}$. Then, $n\left(a_{j}, a_{k}\right)<n\left(a_{j}, a_{l}\right)$. Hence, $f\left(a_{j}, R^{N}\right)=\min _{x \in A \backslash a_{j}} n\left(a_{j}, x\right)=n\left(a_{j}, a_{k}\right)$.

Proposition 6. If there exists a Condorcet cycle at some profile $R^{N}$, then the Condorcet score of an alternative $a_{j}$ is given by $f\left(a_{j}, R^{N}\right)=n\left(a_{j}, a_{k}\right)$ where $a_{k}$ is the unique alternative such that $a_{k} M a_{j}$.

Proof. Straightforward.

As a consequence, we have the following Condorcet scores for the two Condorcet cycles with $A=\left\{a_{1}, a_{2}, a_{3}\right\}$ :

$$
\begin{gathered}
\text { Cycle 1: } a_{2} M a_{1}, a_{1} M a_{3} \text { and } a_{3} M a_{2} \\
\hline f\left(a_{1}, R^{N}\right)=n\left(a_{1}, a_{2}\right)=n_{1}+n_{2}+n_{5} \\
f\left(a_{2}, R^{N}\right)=n\left(a_{2}, a_{3}\right)=n_{1}+n_{3}+n_{4} \\
f\left(a_{3}, R^{N}\right)=n\left(a_{3}, a_{1}\right)=n_{4}+n_{5}+n_{6}
\end{gathered}
$$

and

$$
\begin{gathered}
\text { Cycle 2: } a_{1} M a_{2}, a_{2} M a_{3} \text { and } a_{3} M a_{1} \\
\hline f\left(a_{1}, R^{N}\right)=n\left(a_{1}, a_{3}\right)=n_{1}+n_{2}+n_{3} \\
f\left(a_{2}, R^{N}\right)=n\left(a_{2}, a_{1}\right)=n_{3}+n_{4}+n_{6} \\
f\left(a_{3}, R^{N}\right)=n\left(a_{3}, a_{2}\right)=n_{2}+n_{5}+n_{6}
\end{gathered}
$$

Kemeny's procedure We start by computing the score of each of the six linear orders, from $R_{1}$ to $R_{6}$.

For $R_{1}=a_{1} a_{2} a_{3}, K\left(a_{1}, a_{2}\right)=1, K\left(a_{1}, a_{3}\right)=1, K\left(a_{2}, a_{3}\right)=1$ and $K\left(a_{j}, a_{k}\right)=0$ otherwise. Then $S\left(R_{1}\right)=n\left(a_{1} a_{2}\right)+n\left(a_{1} a_{3}\right)+n\left(a_{2}, a_{3}\right)$.

In the same way, we have : 


$$
\begin{aligned}
& S\left(R_{2}\right)=n\left(a_{1}, a_{2}\right)+n\left(a_{1}, a_{3}\right)+n\left(a_{3}, a_{2}\right) \\
& S\left(R_{3}\right)=n\left(a_{2}, a_{1}\right)+n\left(a_{1}, a_{3}\right)+n\left(a_{2}, a_{3}\right) \\
& S\left(R_{4}\right)=n\left(a_{2}, a_{1}\right)+n\left(a_{3}, a_{1}\right)+n\left(a_{2}, a_{3}\right) \\
& S\left(R_{5}\right)=n\left(a_{1}, a_{2}\right)+n\left(a_{3}, a_{1}\right)+n\left(a_{3}, a_{2}\right) \\
& S\left(R_{6}\right)=n\left(a_{2}, a_{1}\right)+n\left(a_{3}, a_{1}\right)+n\left(a_{3}, a_{2}\right)
\end{aligned}
$$

We can now determine when an alternative is elected under Kemeny's rule. Alternative $a_{1}$ is chosen when individual preferences in the profile are closest to $R_{1}$ or $R_{2}$. This means that $\max \left\{S\left(R_{1}\right), S\left(R_{2}\right)\right\} \geq \max \left\{S\left(R_{3}\right), S\left(R_{4}\right)\right\}$ and $\max \left\{S\left(R_{1}\right), S\left(R_{2}\right)\right\} \geq \max \left\{S\left(R_{5}\right), S\left(R_{6}\right)\right\}$. In the same way $a_{2}$ is the winner if $\max \left\{S\left(R_{3}\right), S\left(R_{4}\right)\right\}>\max \left\{S\left(R_{1}\right), S\left(R_{2}\right)\right\}$ and $\max \left\{S\left(R_{3}\right), S\left(R_{4}\right)\right\}$ $\geq \max \left\{S\left(R_{5}\right), S\left(R_{6}\right)\right\}$. And $a_{3}$ is the winner if $\max \left\{S\left(R_{5}\right), S\left(R_{6}\right)\right\}>\max \left(S\left(R_{1}\right), S\left(R_{2}\right)\right)$ and $\max \left\{S\left(R_{5}\right), S\left(R_{6}\right)\right\}>\max \left\{S\left(R_{3}\right), S\left(R_{4}\right)\right\}$.

As a consequence, we have the following proposition.

Proposition 7. Under Kemeny's rule, if there exists a

1) Condorcet cycle 1, then $k\left(a_{1}, R^{N}\right)=\max \left\{S\left(R_{1}\right), S\left(R_{2}\right)\right\}=S\left(R_{2}\right), k\left(a_{2}, R^{N}\right)=\max \left\{S\left(R_{3}\right)\right.$, $\left.S\left(R_{4}\right)\right\}=S\left(R_{3}\right)$ and $k\left(a_{3}, R^{N}\right)=\max \left\{S\left(R_{5}\right), S\left(R_{6}\right)\right\}=S\left(R_{6}\right)$.

2) Condorcet cycle 2, then $k\left(a_{1}, R^{N}\right)=\max \left\{S\left(R_{1}\right), S\left(R_{2}\right)\right\}=S\left(R_{1}\right), k\left(a_{2}, R^{N}\right)=\max \left\{S\left(R_{3}\right)\right.$, $\left.S\left(R_{4}\right)\right\}=S\left(R_{4}\right)$ and $k\left(a_{3}, R^{N}\right)=\max \left\{S\left(R_{5}\right), S\left(R_{6}\right)\right\}=S\left(R_{5}\right)$.

Proof. With a Condorcet cycle 1, $a_{3} M a_{2}$, which means that $n\left(a_{3}, a_{2}\right)>n\left(a_{2}, a_{3}\right)$. Since $S\left(R_{1}\right)=$ $n\left(a_{1}, a_{2}\right)+n\left(a_{1} a_{3}\right)+n\left(a_{2}, a_{3}\right)$ and $S\left(R_{2}\right)=n\left(a_{1}, a_{2}\right)+n\left(a_{1}, a_{3}\right)+n\left(a_{3}, a_{2}\right)$, then $S\left(R_{2}\right)>S\left(R_{1}\right)$ and $k\left(a_{1}, R^{N}\right)=\max \left\{S\left(R_{1}\right), S\left(R_{2}\right)\right\}=S\left(R_{2}\right)$. With a Condorcet cycle 2, we have the converse, $a_{2} M a_{3}, n\left(a_{2}, a_{3}\right)>n\left(a_{3}, a_{2}\right)$ and $S\left(R_{1}\right)>S\left(R_{2}\right)$. Then $k\left(a_{1}, R^{N}\right)=\max \left\{S\left(R_{1}\right), S\left(R_{2}\right)\right\}=S\left(R_{1}\right)$.

The proof is the same for $\max \left\{S\left(R_{3}\right), S\left(R_{4}\right)\right\}$ and $\max \left\{S\left(R_{5}\right), S\left(R_{6}\right)\right\}$.

From the previous propositions, we can deduce the following results.

Proposition 8. Suppose there exists a Cycle 1 or a Cycle 2. Then for all $\{x, y\} \subseteq\left\{a_{1}, a_{2}, a_{3}\right\}$, $d\left(x, R^{N}\right)-d\left(y, R^{N}\right)=f\left(x, R^{N}\right)-f\left(y, R^{N}\right)=\frac{1}{2}\left[e\left(x, R^{N}\right)-e\left(y, R^{N}\right)\right]=\frac{1}{2}\left[k\left(x, R^{N}\right)-k\left(y, R^{N}\right)\right]$.

Proof. Suppose a Cycle 1 occurs.

Consider $\{x, y\} \subseteq\left\{a_{1}, a_{2}, a_{3}\right\}$. For example $x=a_{1}$ and $y=a_{2}$. It follows that $d\left(a_{1}, R^{N}\right)=$ $\left\lfloor\frac{n+1}{2}\right\rfloor-\left(n_{1}+n_{2}+n_{5}\right)$ and $d\left(a_{2}, R^{N}\right)=\left\lfloor\frac{n+1}{2}\right\rfloor-\left(n_{1}+n_{3}+n_{4}\right) ; f\left(a_{1}, R^{N}\right)=\left(n_{1}+n_{2}+n_{5}\right)$ and $f\left(a_{2}, R^{N}\right)=\left(n_{1}+n_{3}+n_{4}\right) ; e\left(a_{1}, R^{N}\right)=2\left(n_{1}+n_{2}+n_{5}\right)$ and $e\left(a_{2}, R^{N}\right)=2\left(n_{1}+n_{3}+n_{4}\right)$; $k\left(a_{1}, R^{N}\right)=S\left(R_{2}\right)=n\left(a_{1}, a_{2}\right)+n\left(a_{1}, a_{3}\right)+n\left(a_{3}, a_{2}\right)=2 n_{1}+3 n_{2}+n_{3}+2 n_{5}+n_{6}$ and $k\left(a_{2}, R^{N}\right)=$ $S\left(R_{3}\right)=n\left(a_{2}, a_{1}\right)+n\left(a_{1}, a_{3}\right)+n\left(a_{2}, a_{3}\right)=2 n_{1}+n_{2}+3 n_{3}+2 n_{4}+n_{6}$.

Then $d\left(a_{1}, R^{N}\right)-d\left(a_{2}, R^{N}\right)=\left(n_{2}+n_{5}\right)-\left(n_{3}+n_{4}\right), f\left(a_{1}, R^{N}\right)-f\left(a_{2}, R^{N}\right)=\left(n_{2}+n_{5}\right)-\left(n_{3}+n_{4}\right)$, $e\left(a_{1}, R^{N}\right)-e\left(a_{2}, R^{N}\right)=2\left[\left(n_{2}+n_{5}\right)-\left(n_{3}+n_{4}\right)\right]$ and $k\left(a_{1}, R^{N}\right)-k\left(a_{2}, R^{N}\right)=2\left[\left(n_{2}+n_{5}\right)-\left(n_{3}+n_{4}\right)\right]$.

Consequently, $d\left(a_{1}, R^{N}\right)-d\left(a_{2}, R^{N}\right)=f\left(a_{1}, R^{N}\right)-f\left(a_{2}, R^{N}\right)=\frac{1}{2}\left[e\left(a_{1}, R^{N}\right)-e\left(a_{2}, R^{N}\right)\right]=$ $\frac{1}{2}\left[k\left(a_{1}, R^{N}\right)-k\left(a_{2}, R^{N}\right)\right]=\left(n_{2}+n_{5}\right)-\left(n_{3}+n_{4}\right)$.

The same observation can easily be shown for $\left\{a_{1}, a_{3}\right\}$ and $\left\{a_{2}, a_{3}\right\}$; and even when Cycle 1 is replaced with Cycle 2.

Corollary 1. Suppose Cycle 1 or Cycle 2 occur. Then $F_{3}, F_{4}, F_{5}$ and $F_{6}$ select the same winner.

Proof. Straightforward.

This corollary shows that when we have a cycle, Dodgson, Young, Condorcet and Kemeny's procedures always select the same winner. We will next show that this is also true when there is no Condorcet cycle. 


\subsubsection{Other cases}

Proposition 9. Suppose there is no Cycle 1 or Cycle 2 at some profile. Then $F_{1}, F_{3}, F_{4}, F_{5}, F_{6}$, $F_{7}$ and $F_{8}$ select the same winner.

Proof. We examine all possible cases and observe that the result holds.

(i) Not $\left(a_{2} M a_{1}\right)$ and not $\left(a_{3} M a_{1}\right)$. Then $a_{1}$ belongs to the choice set of $C_{j}, j=1,3,4,5,6,7,8$. Using the tie-breaking rule, $a_{1}$ is selected by $F_{j}, j=1,3,4,5,6,7,8$.

(ii) $a_{2} M a_{1}$

Two subcases are distinguished.

If not $\left(a_{3} M a_{2}\right)$ occurs, then $a_{2}$ but not $a_{1}$ belongs to the choice set of $C_{j}, j=1,3,4,5,6,7,8$. Therefore $a_{2}$ is selected by $F_{j}, j=1,3,4,5,6,7,8$.

Otherwise $a_{3} M a_{2}$. Then $a_{2} M a_{1}$ and $a_{3} M a_{2}$ occur simultaneously. Since there is no cycle, not $\left(a_{1} M a_{3}\right)$ stands. Therefore $a_{3}$ is the unique candidate in the choice set of $C_{j}, j=1,3,4,5,6,7,8$. Then $F_{j}, j=1,3,4,5,6,7,8$ selects $a_{3}$.

(iii) $a_{3} M a_{1}$ and not $\left(a_{2} M a_{1}\right)$

Three cases are in consideration.

If $a_{3} M a_{2}$, then $a_{3}$ is the unique Condorcet winner and is selected by $F_{j}, j=1,3,4,5,6,7,8$.

If $a_{2} M a_{3}$, then not $\left(a_{1} M a_{2}\right)$ occurs since there is no cycle. Moreover since not $\left(a_{2} M a_{1}\right)$ holds, $a_{2}$ ties $a_{1}$. Therefore $a_{2}$ is the unique candidate in the choice set of $C_{j}, j=1,3,4,5,6,7,8$. Thus $F_{j}, j=1,3,4,5,6,7,8$ all select $a_{2}$.

Otherwise $a_{2}$ ties $a_{3}$. Since not $\left(a_{2} M a_{1}\right)$ holds, there are two possibilities: either $a_{1}$ ties $a_{2}$, or $a_{1} M a_{2}$.

If $a_{1} M a_{2}$, then $a_{3}$ is the unique outcome in the choice set of $C_{j}, j=1,3,4,5,6,7,8$ and is then selected by $F_{j}, j=1,3,4,5,6,7,8$.

If $a_{1}$ ties $a_{2}$, then $a_{2}$ but not $a_{1}$ is in the choice set of $C_{j}, j=1,3,4,5,6,7,8$ and is then selected by $F_{j}, j=1,3,4,5,6,7,8$.

The theorem below follows from Corollary 1 and Proposition 9.

Theorem 1. With three alternatives and for all profile, Dodgson's rule, Young's rule, Condorcet's rule and Kemeny's rule always select the same winner.

Proof. The proof is straighforward from the previous propositions.

Theorem 2. With three alternatives and for all profile, Fishburn's rule and Schwartz's rule always select the same winner.

Proof. The proof is straighforward from Proposition 9. In fact the two procedures coincide when there is no cycle. Moreover by definition, the choice set from the two procedures contains the three alternatives when there is a cycle and by the tie-breaking rule, $a_{1}$ is selected by $F_{j}, j=7,8$. Therefore $F_{7}=F_{8}$.

It can easily be checked that with more than three alternatives, the above theorems are no longer valid.

In summary, in a three-candidate context, the nine procedures can be reorganized into five classes, three of which are singletons.

Indeed, the criterion we use to distinguish those classes is the specific way they select the outcome of the election when there is no Condorcet winner.

- Whenever there is a cycle, Copeland's function directly relies on the tie-breaking device. 
- Under amendment function, $a_{1}$ and $a_{2}$ can be elected if and only if they are Condorcet winners; in all other cases, the winner is $a_{3}$.

All other functions are equivalent when there is no cycle (see Proposition 9). However,

- Black's function systematically chooses the Borda winner and, if necessary, uses the tiebreaking mechanism.

- Each of Dodgson's, Young's, Condorcet's and Kemeny's rules uses a different way to determine the outcome when there is no Condorcet winner, but all these ways are equivalent.

- Finally, Schwartz's and Fishburn's rules, though based on different majority mechanisms when there is no Condorcet winner, are trivially equivalent in the three-election case.

\section{Reinforcement axiom}

We first present the reinforcement axiom property more formally.

Definition 3. Given $T_{1}$ and $T_{2}$, an $S C F F$ satisfies $R A$ if for any $R^{T_{1}} \in L^{T_{1}}$ and $R^{T_{2}} \in L^{T_{2}}$ and for all $x \in A$,

$$
\left[F\left(R^{T_{1}}\right)=x \text { and } F\left(R^{T_{2}}\right)=x\right] \Longrightarrow F\left(R^{N}\right)=x
$$

Alternatively,

Definition 4. Given $T_{1}$ and $T_{2}$, an $S C F F$ violates $R A$ if there exist $R^{T_{1}} \in L^{T_{1}}, R^{T_{2}} \in L^{T_{2}}$ and $\{x, y\} \subseteq A, x \neq y$, such that

$$
F\left(R^{T_{1}}\right)=x, F\left(R^{T_{2}}\right)=x \text { and } F\left(R^{N}\right)=y
$$

Smith (1973) and Young (1975a) show that all Condorcet social procedures violate the $R A$. In Example 1, we present a case of violation of $R A$ by a Condorcet rule.

Example 1. Consider the Copeland procedure, and assume that $R^{T_{1}} \in L^{T_{1}}$ and $R^{T_{2}} \in L^{T_{2}}$ are as

\begin{tabular}{|c|c|c|c|c|c|c|}
\hline Profiles & \multicolumn{3}{|c|}{$R^{T_{1}}$} & \multicolumn{3}{|c|}{$R^{T_{2}}$} \\
\hline Voters & 4 & 1 & 1 & 5 & 4 & 5 \\
\hline & $w$ & $y$ & $y$ & $w$ & $z$ & $y$ \\
\hline & $y$ & $z$ & $x$ & $z$ & $x$ & $w$ \\
\hline & $x$ & $w$ & $z$ & $x$ & $y$ & $x$ \\
\hline & $z$ & $x$ & $w$ & $y$ & $w$ & $z$ \\
\hline
\end{tabular}
below:

Then the scores are as follows

Separate groups

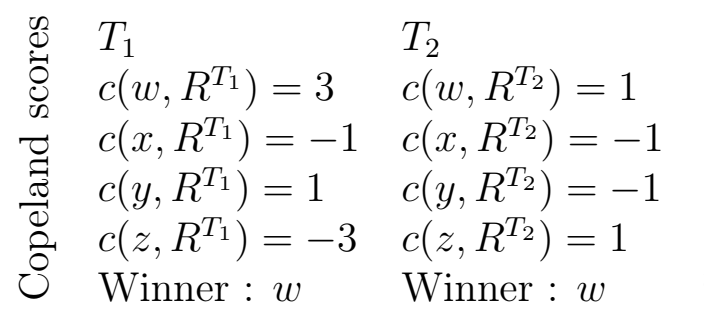

The whole electorate

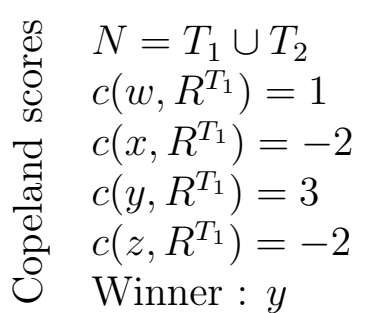


This shows that the Copeland procedure violates $R A: F\left(R^{T_{1}}\right)=w, F\left(R^{T_{2}}\right)=w$, but $F\left(R^{N}\right)=$ $y$.

Next, we identify conditions on the number of voters, under which the violation of $R A$ is susceptible to occur for all the Condorcet procedures introduced above - and it appears that this is the case roughly as soon as the number of voters is equal to 7.

This is reminiscent of Young's (1975a) result on all Condorcet procedures.

Proposition 10. With at least 13 voters and at least three candidates, all Condorcet procedures violate the reinforcement axiom.

Proof. See Moulin (1988), Theorem 9.2, page 237.

The above result covers all Condorcet voting procedures. However, for the procedures under study in this paper, we obtain slightly different versions of Proposition 10.

Proposition 11. In three-candidate elections with 7 voters, all Condorcet procedures $F_{j}$ with $j=1,2, \ldots, 9$ violate the reinforcement axiom.

Proof. Let $F_{j}$ be a Condorcet procedure with $j=1,2, \ldots, 8$;

Case 1: Suppose that $n$ is odd. By assumption on $n$, there exists a non negative integer $p$ such that $n=7+2 p$. Consider the following profiles:

\begin{tabular}{|c|c|c|c|c|c|c|c|c|c|c|c|}
\hline \multicolumn{6}{|l|}{$R^{T_{1}}$} & \multicolumn{6}{|c|}{$R^{T_{2}}$} \\
\hline $1+p$ & 0 & 1 & 0 & 0 & $p$ & 1 & 1 & 1 & 0 & 0 & 2 \\
\hline$x$ & $x$ & $y$ & $y$ & $z$ & $z$ & $x$ & $x$ & $y$ & $y$ & $z$ & $z$ \\
\hline$y$ & $z$ & $x$ & $z$ & $x$ & $y$ & $y$ & $z$ & $x$ & $z$ & $x$ & $y$ \\
\hline$z$ & $y$ & $z$ & $x$ & $y$ & $x$ & $z$ & $y$ & $z$ & $x$ & $y$ & $x$ \\
\hline
\end{tabular}

In profile $R^{T_{1}}, 2+p$ individuals prefer $x$ to $z$, versus $p$ individuals who prefer $z$ to $x$. Since $p \geq 0$, by definition $x M z$. Likewise $y M z$ since $2+p$ prefer $y$ to $z$. And $x$ is tied with $y$ since $1+p$ individuals prefer $x$ to $y$ and $1+p$ prefer $y$ to $x$. By definition, for each $C_{j}$ with $j=1,2, \ldots, 8$, $C_{j}\left(R^{T_{1}}\right)=\{x, y\}$. By the lexicographic order, $F_{j}\left(R^{T_{1}}\right)=x$, for $j=1,2, \ldots, 8$.

In $R^{T_{2}}$, with 3 favorable votes versus $2, x$ is preferred to $z, y$ to $x$ and $z$ to $y$, then $x M z$, $z M y$ and $y M x$. Then we have a Condorcet cycle 2. By definition of $C_{1}, b\left(x, R^{T_{2}}\right)=2+3=5$, $b\left(y, R^{T_{2}}\right)=3+2=5$ and $b\left(z, R^{T_{2}}\right)=2+3=5$, then $C_{1}\left(R^{T_{2}}\right)=\{x, y, z\}$ and $F_{1}\left(R^{T_{2}}\right)=x$. We have also $c\left(x, R^{T_{2}}\right)=1-1=0, c\left(y, R^{T_{2}}\right)=1-1=0$ and $c\left(z, R^{T_{2}}\right)=1-1=0$, then $C_{2}\left(R^{T_{2}}\right)=\{x, y, z\}$ and $F_{2}\left(R^{T_{2}}\right)=x$. From proposition 5 , we know that $f\left(x, R^{T_{2}}\right)=n(x, y)=2$, $f\left(y, R^{T_{2}}\right)=n(y, z)=2$ and $f\left(z, R^{T_{2}}\right)=n(z, x)=2$, then $C_{5}\left(R^{T_{2}}\right)=\{x, y, z\}$ and $F_{5}\left(R^{T_{2}}\right)=x$. By theorem $1, F_{j}\left(R^{T_{2}}\right)=x$ for $j=3,4,5,6$. And finally, $C_{7}\left(R^{T_{2}}\right)=C_{8}\left(R^{T_{2}}\right)=\{x, y, z\}$, since there are clearly no Schwartz and no Fishburn relations over $\{x, y, z\}$. Then, $F_{7}\left(R^{T_{2}}\right)=F_{8}\left(R^{T_{2}}\right)=x$. We can then conclude that $F_{j}\left(R^{T_{2}}\right)=x$, for $j=1,2, \ldots, 8$.

In $R^{N}, y$ is a Condorcet winner, since $y M x$ and $y M z$. Indeed, $4+p$ versus $3+p$ individuals prefer $y$ to $x$ and $4+p$ versus $3+p$ individuals prefer $y$ to $z$. That is $F_{j}\left(R^{N}\right)=y$ for $j=1,2, \ldots, 8$.

Case 2: Suppose that $n$ is even. By assumption on $n$, there exists a non negative integer $p$ such that $n=8+2 p$. Consider the following profiles:

\begin{tabular}{|c|c|c|c|c|c|c|c|c|c|c|c|}
\hline \multicolumn{6}{|l|}{$R^{T_{1}}$} & \multicolumn{6}{|c|}{$R^{T_{2}}$} \\
\hline $1+p$ & 0 & 1 & 0 & 0 & $p$ & 0 & 2 & 2 & 0 & 0 & 2 \\
\hline$x$ & $x$ & $y$ & $y$ & $z$ & $z$ & $x$ & $x$ & $y$ & $y$ & $z$ & $z$ \\
\hline$y$ & $z$ & $x$ & $z$ & $x$ & $y$ & $y$ & $z$ & $x$ & $z$ & $x$ & $y$ \\
\hline$z$ & $y$ & $y$ & $x$ & $y$ & $x$ & $z$ & $y$ & $y$ & $x$ & $y$ & $x$ \\
\hline
\end{tabular}


Using very similar arguments as in the previous case one can easily check that $F_{j}\left(R^{T_{1}}\right)=x$, $F_{j}\left(R^{T_{2}}\right)=x$ and $F_{j}\left(R^{N}\right)=y$ for $j=1,2, \ldots, 8$.

It then appears that in all cases considered above, all Condorcet procedures violate Young reinforcement axiom; and this concludes the proof for $j=1,2, \ldots, 8$. For $j=9$, with the same reasoning as above, we reach the same conclusion, from the two following situations:

\begin{tabular}{|c|c|c|c|c|c|c|c|c|c|c|c|}
\hline \multicolumn{6}{|c|}{$R^{T_{1}}$} & \multicolumn{6}{|c|}{$R^{T_{2}}$} \\
\hline$p$ & 0 & 0 & 0 & $2+p$ & 0 & 0 & 2 & 2 & 0 & 0 & 1 \\
\hline$x$ & $x$ & $y$ & $y$ & $z$ & $z$ & $x$ & $x$ & $y$ & $y$ & $z$ & $z$ \\
\hline$y$ & $z$ & $x$ & $z$ & $x$ & $y$ & $y$ & $z$ & $x$ & $z$ & $x$ & $y$ \\
\hline$z$ & $y$ & $z$ & $x$ & $y$ & $x$ & $z$ & $y$ & $z$ & $x$ & $y$ & $x$ \\
\hline
\end{tabular}

if $n$ is odd, and

\begin{tabular}{|c|c|c|c|c|c|c|c|c|c|c|c|}
\hline \multicolumn{6}{|c|}{$R^{T_{1}}$} & \multicolumn{6}{|c|}{$R^{T_{2}}$} \\
\hline$p$ & 0 & 0 & 0 & $1+p$ & 0 & 2 & 1 & 1 & 0 & 0 & 3 \\
\hline$x$ & $x$ & $y$ & $y$ & $z$ & $z$ & $x$ & $x$ & $y$ & $y$ & $z$ & $z$ \\
\hline$y$ & $z$ & $x$ & $z$ & $x$ & $y$ & $y$ & $z$ & $x$ & $z$ & $x$ & $y$ \\
\hline$z$ & $y$ & $z$ & $x$ & $y$ & $x$ & $z$ & $y$ & $z$ & $x$ & $y$ & $x$ \\
\hline
\end{tabular}

if $n$ is even. And this ends the proof.

As a direct consequence of the preceding proposition, the following holds:

Proposition 12. With at least seven voters and at least three candidates, all Condorcet procedure $F_{j}$ with $j=1,2, \ldots, 9$ violate the reinforcement axiom.

Proof. Suppose $A=\left\{x, y, z, a_{4}, a_{5}, \ldots, a_{m}\right\}$ and let $F_{j}$ be a Condorcet procedure. Consider the distinct cases in the proof of Proposition 11 and the corresponding profiles $R^{T_{1}}$ and $R^{T_{2}}$. Now, construct two new profiles $\underline{R}^{T_{1}}$ and $\underline{R}^{T_{2}}$ from $R^{T_{1}}$ and $R^{T_{2}}$ respectively, in such a way that alternative $a_{4}$ appears at the fourth position in each individual preference relation, $a_{5}$ appears at the fifth position, and so on. Each candidate in $\{x, y, z\}$ is then prefered by a majority of individuals to all candidates in $\left\{a_{4}, a_{5}, \ldots, a_{m}\right\}$. It follows that the winners are exactly the same as with $R^{T_{1}}$, $R^{T_{2}}$ and $R^{N}$ respectively. That is $F\left(\underline{R}^{T_{1}}\right)=x, F\left(\underline{R}^{T_{2}}\right)=x$ and $F\left(\underline{R}^{N}\right)=y$. Consequently, $F_{j}$ violates the reinforcement axiom.

The two propositions show that all Condorcet procedures introduced above violate $R A$ when the number of voters is equal to or greater than seven, provided that the number of alternatives is at least three. In other words for all the procedures studied in this paper, we can always find a profile at which $R A$ is violated, with at least seven voters and at least three alternatives. Below seven voters, we can find some pathological profiles, but not for all rules. Indeed, the reader can easily check that the minimum number of voters at which the phenomenon arise is three for Copeland, five for Fishburn, Schwartz and amendment. For the other rules, there is no case below seven. Note also, that it straightforwardly appears that with two alternatives there exists no Condorcet procedure which violates $R A$.

We will now turn to the evaluation on how frequent Condorcet procedures violate $R A$. In the next section, we focus on the special case of three alternatives. 


\section{The likelihood of reinforcement violation}

Our main purpose in this section is to compare the nine Condorcet rules described above in terms of their susceptibility to violate $R A$. We only study the three-alternative case in this paper, since with four or more alternatives, computations are much more involved.

In order to do that we evaluate the proportion of preference profiles at which the violation of $R A$ arises. We first have a typology of the various profiles at which this violation occurs. We can notice that if voting is restricted to profiles in which at least one Condorcet winner exists, then selecting the Condorcet winners satisfies $R A$. Indeed, if a majority in each of the two constituencies prefers $a$ to $x$, then a majority in the whole constituency prefers $a$ to $x$. Thus, the violation of $R A$ is due to majority cycles.

More precisely, given a voting rule, situations in which the voting rule violates $R A$ are completely described by a set of linear inequalities (technicalities are available from the authors upon simple request). And from this typology, by the use of computerised evaluation processes, we obtain various frequencies measuring the susceptibility of this rule to violate $R A$.

The computer evaluation process consists in simulations using the traditional Monte Carlo method. Computer simulations are very often used in social choice in order to determine the frequencies of paradoxes, e.g., Nitzan (1985) or Kelly (1993) among others. The Monte Carlo simulations method is useful when a problem cannot be solved analytically.

Its principle is as follows: (i) we choose a probabilistic hypothesis, that is the way probabilities are assigned to events; (ii) we randomly generate under each probability approach a set of 100,000 profiles (a greater number does not significantly improve the results); and (iii) for each voting rule under consideration, we then count the total number of pathological profiles among the list of drawn profiles. The estimation of the likelihood that the rule violates $R A$ is then derived as the following ratio:

\section{Number of occurences of pathological profiles randomly generated}

Total number of profiles randomly generated

Note that the values we obtain are not exact probabilities, but rather estimates. For example, a value equal to 0 doesn't necessarily mean that the phenomenon cannot at all occur, but in fact, simply means that its probability of occurrence is very small.

Two traditional probabilistic hypotheses are taken into account: impartial culture (IC) and impartial anonymous culture (IAC). Both are based on an equal probability assumption, but not exactly in the same way. Under the IAC probabilistic model, all anonymous preference profiles are equally likely to be observed: for every possible preference order, the number of voters reporting that order is drawn, in such a way that the total number of voters be equal to $n$. More precisely, for each $n$ and each linear order we draw randomly the number $n_{1}$ of individuals with the first linear order. And then, again randomly, we draw the number $n_{2}$ of individuals with the second linear order between 0 and $n-n_{1}$, and so on. Under the IC probabilistic model and given any voter, the six rankings are equally likely to be the preference relation of this voter. In other words, for each voter, every preference order has an equal chance to be drawn ( $\frac{1}{6}$ in the three-alternative case). For a more detailed discussion on these probabilistic models, see Reggenwetter et al. (2006), or Berg and Lepelley (1993), or Lepelley, Louichi, and Smaoui (2008).

In this section, for each probabilistic hypothesis and each rule under study, we present tables of values and graphs corresponding to some values of the total number of voters.

Beside the results with Monte Carlo simulations, we also provide analytical results under the IAC hypothesis when the number of individuals is infinitely large. Within this framework, we use 
an analytical method — as distinguished from computer simulations — and provide exact relations giving the proportion of anonymous profiles vulnerable to the violation of $R A$. These results are obtained by the use of the technique of Fishburn and Gehrlein (1976).

\subsection{Impartial anonymous culture}

\subsubsection{Simulations results under IAC}

We consider the case where $n \in\{25,50,75,100\}$ and $t$ (the size of any of the two constituencies) changes from 1 to at most $\frac{n}{2}$ (Tables 1 and 2$)^{3}$. Note that cases where $t \geq \frac{n}{2}$ are symmetrical to those where $t \leq \frac{n}{2}$. For example, for $n=25$, the results are the same with $t=1$ and $t=24$.

Table 1 (IAC 1) Frequencies of violation of $R A$ for Condorcet procedures with $n=25$ and $n=50$

\begin{tabular}{|c|c|c|c|c|c|c|c|c|c|c|}
\hline \multirow[t]{2}{*}{$t$} & \multicolumn{5}{|l|}{$n=25$} & \multicolumn{5}{|l|}{$n=50$} \\
\hline & $F_{1}$ & $F_{2}$ & $F_{3}, F_{4}, F_{5}, F_{6}$ & $F_{7}, F_{8}$ & $F_{9}$ & $F_{1}$ & $F_{2}$ & $F_{3}, F_{4}, F_{5}, F_{6}$ & $F_{7}, F_{8}$ & $F_{9}$ \\
\hline 1 & $5,54 \mathrm{E}-03$ & $0,00 \mathrm{E}+00$ & $0,00 \mathrm{E}+00$ & $0,00 \mathrm{E}+00$ & $0,00 \mathrm{E}+00$ & $1,22 \mathrm{E}-02$ & $3,10 \mathrm{E}-03$ & $0,00 \mathrm{E}+00$ & $3,10 \mathrm{E}-03$ & $1,98 \mathrm{E}-03$ \\
\hline 2 & $7,16 \mathrm{E}-03$ & $5,08 \mathrm{E}-03$ & $4,40 \mathrm{E}-04$ & $5,26 \mathrm{E}-03$ & $2,36 \mathrm{E}-03$ & $7,16 \mathrm{E}-03$ & $2,04 \mathrm{E}-03$ & $1,20 \mathrm{E}-04$ & $2,22 \mathrm{E}-03$ & $1,18 \mathrm{E}-03$ \\
\hline 3 & $4,54 \mathrm{E}-03$ & $5,08 \mathrm{E}-03$ & $1,02 \mathrm{E}-03$ & $2,34 \mathrm{E}-03$ & $1,18 \mathrm{E}-03$ & $1,01 \mathrm{E}-02$ & $4,20 \mathrm{E}-03$ & $8,80 \mathrm{E}-04$ & $4,22 \mathrm{E}-03$ & $2,80 \mathrm{E}-03$ \\
\hline 4 & $5,84 \mathrm{E}-03$ & $5,78 \mathrm{E}-03$ & $1,86 \mathrm{E}-03$ & $6,94 \mathrm{E}-03$ & $2,36 \mathrm{E}-03$ & $6,62 \mathrm{E}-03$ & $3,02 \mathrm{E}-03$ & $1,04 \mathrm{E}-03$ & $3,48 \mathrm{E}-03$ & $1,76 \mathrm{E}-03$ \\
\hline 5 & $3,96 \mathrm{E}-03$ & $2,54 \mathrm{E}-03$ & $1,50 \mathrm{E}-03$ & $2,58 \mathrm{E}-03$ & $1,34 \mathrm{E}-03$ & $8,80 \mathrm{E}-03$ & $5,50 \mathrm{E}-03$ & $1,12 \mathrm{E}-03$ & $5,60 \mathrm{E}-03$ & $4,20 \mathrm{E}-03$ \\
\hline 6 & $6,54 \mathrm{E}-03$ & $6,60 \mathrm{E}-03$ & $2,94 \mathrm{E}-03$ & $8,16 \mathrm{E}-03$ & $2,70 \mathrm{E}-03$ & $5,50 \mathrm{E}-03$ & $3,56 \mathrm{E}-03$ & $1,42 \mathrm{E}-03$ & $4,04 \mathrm{E}-03$ & $1,88 \mathrm{E}-03$ \\
\hline 7 & $4,80 \mathrm{E}-03$ & $3,10 \mathrm{E}-03$ & $2,04 \mathrm{E}-03$ & $3,14 \mathrm{E}-03$ & $2,02 \mathrm{E}-03$ & $8,28 \mathrm{E}-03$ & $5,12 \mathrm{E}-03$ & $1,10 \mathrm{E}-03$ & $5,36 \mathrm{E}-03$ & $4,26 \mathrm{E}-03$ \\
\hline 8 & $5,96 \mathrm{E}-03$ & $8,26 \mathrm{E}-03$ & $3,76 \mathrm{E}-03$ & $9,30 \mathrm{E}-03$ & $4,56 \mathrm{E}-03$ & $5,98 \mathrm{E}-03$ & $4,20 \mathrm{E}-03$ & $1,64 \mathrm{E}-03$ & $4,58 \mathrm{E}-03$ & $2,12 \mathrm{E}-03$ \\
\hline 9 & $3,76 \mathrm{E}-03$ & $3,18 \mathrm{E}-03$ & $1,64 \mathrm{E}-04$ & $3,10 \mathrm{E}-03$ & $2,54 \mathrm{E}-03$ & $7,40 \mathrm{E}-03$ & $5,96 \mathrm{E}-03$ & $1,36 \mathrm{E}-03$ & $6,06 \mathrm{E}-03$ & $5,50 \mathrm{E}-03$ \\
\hline 10 & $5,40 \mathrm{E}-03$ & $7,78 \mathrm{E}-03$ & $3,46 \mathrm{E}-03$ & $8,80 \mathrm{E}-03$ & $4,06 \mathrm{E}-03$ & $5,32 \mathrm{E}-03$ & $4,56 \mathrm{E}-03$ & $1,70 \mathrm{E}-03$ & $5,02 \mathrm{E}-03$ & $2,78 \mathrm{E}-03$ \\
\hline 15 & & & & & & $6,54 \mathrm{E}-03$ & $6,18 \mathrm{E}-03$ & $2,08 \mathrm{E}-03$ & $6,24 \mathrm{E}-03$ & $6,68 \mathrm{E}-03$ \\
\hline 20 & & & & & & $3,48 \mathrm{E}-03$ & $4,04 \mathrm{E}-03$ & $1,88 \mathrm{E}-04$ & $4,14 \mathrm{E}-03$ & $4,40 \mathrm{E}-03$ \\
\hline 25 & & & & & & $3,74 \mathrm{E}-03$ & $4,52 \mathrm{E}-03$ & $1,60 \mathrm{E}-04$ & $4,66 \mathrm{E}-03$ & $7,28 \mathrm{E}-03$ \\
\hline
\end{tabular}

\footnotetext{
${ }^{3}$ Note that in the tables, the notation $x \mathrm{E}-y$ is used as an equivalent for $x \times 10^{-y}$, where $x$ and $y$ are real numbers.
} 
Table 2 (IAC 2) Frequencies of violation of $R A$ for Condorcet procedures with $n=75$ and $n=100$

\begin{tabular}{|c|c|c|c|c|c|c|c|c|c|c|}
\hline \multirow[t]{2}{*}{$t$} & \multicolumn{5}{|l|}{$n=75$} & \multicolumn{5}{|l|}{$n=100$} \\
\hline & $F_{1}$ & $F_{2}$ & $F_{3}, F_{4}, F_{5}, F_{6}$ & $F_{7}, F_{8}$ & $F_{9}$ & $F_{1}$ & $F_{2}$ & $F_{3}, F_{4}, F_{5}, F_{6}$ & $F_{7}, F_{8}$ & $F_{9}$ \\
\hline 1 & $1,07 \mathrm{E}-02$ & $0,00 \mathrm{E}+00$ & $0,00 \mathrm{E}+00$ & $0,00 \mathrm{E}+00$ & $0,00 \mathrm{E}+00$ & $1,29 \mathrm{E}-02$ & $1,58 \mathrm{E}-03$ & $0,00 \mathrm{E}+00$ & $1,58 \mathrm{E}-03$ & $6,80 \mathrm{E}-04$ \\
\hline 2 & $1,01 \mathrm{E}-02$ & $1,90 \mathrm{E}-03$ & $1,20 \mathrm{E}-04$ & $2,04 \mathrm{E}-03$ & $9,20 \mathrm{E}-04$ & $9,32 \mathrm{E}-03$ & $1,38 \mathrm{E}-03$ & $1,40 \mathrm{E}-04$ & $1,44 \mathrm{E}-03$ & $7,00 \mathrm{E}-04$ \\
\hline 3 & $9,86 \mathrm{E}-03$ & $1,42 \mathrm{E}-03$ & $4,80 \mathrm{E}-04$ & $1,42 \mathrm{E}-03$ & $7,00 \mathrm{E}-04$ & $1,20 \mathrm{E}-02$ & $3,10 \mathrm{E}-03$ & $4,00 \mathrm{E}-04$ & $3,14 \mathrm{E}-03$ & $1,66 \mathrm{E}-03$ \\
\hline 4 & $9,06 \mathrm{E}-03$ & $2,54 \mathrm{E}-03$ & $8,40 \mathrm{E}-04$ & $2,88 \mathrm{E}-03$ & $1,28 \mathrm{E}-03$ & $8,30 \mathrm{E}-03$ & $1,90 \mathrm{E}-03$ & $6,20 \mathrm{E}-04$ & $2,10 \mathrm{E}-03$ & $1,04 \mathrm{E}-03$ \\
\hline 5 & $8,42 \mathrm{E}-03$ & $1,80 \mathrm{E}-03$ & $8,00 \mathrm{E}-04$ & $1,74 \mathrm{E}-03$ & $1,12 \mathrm{E}-03$ & $1,13 \mathrm{E}-02$ & $3,64 \mathrm{E}-03$ & $7,80 \mathrm{E}-04$ & $3,78 \mathrm{E}-03$ & $2,28 \mathrm{E}-03$ \\
\hline 6 & $8,48 \mathrm{E}-03$ & $3,56 \mathrm{E}-03$ & $1,22 \mathrm{E}-03$ & $4,16 \mathrm{E}-03$ & $1,20 \mathrm{E}-03$ & $7,98 \mathrm{E}-03$ & $2,38 \mathrm{E}-03$ & $7,80 \mathrm{E}-04$ & $2,66 \mathrm{E}-03$ & $1,04 \mathrm{E}-03$ \\
\hline 7 & $8,58 \mathrm{E}-03$ & $1,64 \mathrm{E}-03$ & $1,14 \mathrm{E}-03$ & $1,70 \mathrm{E}-03$ & $1,26 \mathrm{E}-03$ & $1,02 \mathrm{E}-02$ & $2,88 \mathrm{E}-03$ & $8,80 \mathrm{E}-04$ & $3,06 \mathrm{E}-03$ & $2,38 \mathrm{E}-03$ \\
\hline 8 & $8,62 \mathrm{E}-03$ & $4,22 \mathrm{E}-03$ & $1,54 \mathrm{E}-03$ & $4,76 \mathrm{E}-03$ & $1,86 \mathrm{E}-03$ & $8,22 \mathrm{E}-03$ & $2,80 \mathrm{E}-03$ & $9,60 \mathrm{E}-04$ & $3,12 \mathrm{E}-03$ & $1,38 \mathrm{E}-03$ \\
\hline 9 & $7,24 \mathrm{E}-03$ & $2,32 \mathrm{E}-03$ & $1,16 \mathrm{E}-03$ & $2,34 \mathrm{E}-03$ & $1,72 \mathrm{E}-03$ & $9,94 \mathrm{E}-03$ & $3,78 \mathrm{E}-03$ & $1,20 \mathrm{E}-03$ & $3,86 \mathrm{E}-03$ & $3,64 \mathrm{E}-03$ \\
\hline 10 & $8,48 \mathrm{E}-03$ & $5,04 \mathrm{E}-03$ & $1,52 \mathrm{E}-03$ & $5,52 \mathrm{E}-03$ & $2,60 \mathrm{E}-03$ & $8,02 \mathrm{E}-03$ & $3,66 \mathrm{E}-03$ & $1,18 \mathrm{E}-03$ & $3,86 \mathrm{E}-03$ & $1,86 \mathrm{E}-04$ \\
\hline 15 & $6,98 \mathrm{E}-03$ & $3,66 \mathrm{E}-03$ & $1,70 \mathrm{E}-03$ & $3,72 \mathrm{E}-03$ & $2,48 \mathrm{E}-03$ & $8,16 \mathrm{E}-03$ & $4,36 \mathrm{E}-03$ & $1,28 \mathrm{E}-03$ & $4,40 \mathrm{E}-03$ & $4,38 \mathrm{E}-03$ \\
\hline 20 & $6,52 \mathrm{E}-03$ & $6,88 \mathrm{E}-03$ & $2,26 \mathrm{E}-03$ & $6,80 \mathrm{E}-03$ & $4,04 \mathrm{E}-03$ & $6,52 \mathrm{E}-03$ & $4,96 \mathrm{E}-03$ & $1,74 \mathrm{E}-03$ & $4,88 \mathrm{E}-03$ & $2,76 \mathrm{E}-03$ \\
\hline 25 & $4,74 \mathrm{E}-03$ & $4,16 \mathrm{E}-03$ & $1,92 \mathrm{E}-03$ & $4,20 \mathrm{E}-03$ & $4,36 \mathrm{E}-03$ & $6,82 \mathrm{E}-03$ & $6,06 \mathrm{E}-03$ & $2,08 \mathrm{E}-03$ & $6,28 \mathrm{E}-03$ & $5,24 \mathrm{E}-03$ \\
\hline 30 & $4,80 \mathrm{E}-03$ & $6,74 \mathrm{E}-03$ & $1,76 \mathrm{E}-03$ & $7,00 \mathrm{E}-03$ & $5,48 \mathrm{E}-03$ & $5,78 \mathrm{E}-03$ & $5,00 \mathrm{E}-03$ & $1,64 \mathrm{E}-03$ & $5,18 \mathrm{E}-03$ & $4,36 \mathrm{E}-03$ \\
\hline 35 & $3,40 \mathrm{E}-03$ & $4,02 \mathrm{E}-03$ & $1,48 \mathrm{E}-03$ & $4,10 \mathrm{E}-03$ & $4,08 \mathrm{E}-03$ & $5,50 \mathrm{E}-03$ & $6,28 \mathrm{E}-03$ & $1,68 \mathrm{E}-03$ & $6,68 \mathrm{E}-03$ & $5,80 \mathrm{E}-03$ \\
\hline 40 & & & & & & $4,44 \mathrm{E}-03$ & $5,44 \mathrm{E}-03$ & $1,44 \mathrm{E}-03$ & $5,60 \mathrm{E}-03$ & $4,88 \mathrm{E}-03$ \\
\hline 45 & & & & & & $4,18 \mathrm{E}-03$ & $5,46 \mathrm{E}-03$ & $1,68 \mathrm{E}-03$ & $5,50 \mathrm{E}-03$ & $5,60 \mathrm{E}-03$ \\
\hline 50 & & & & & & $3,12 \mathrm{E}-03$ & $3,90 \mathrm{E}-03$ & $1,38 \mathrm{E}-03$ & $3,88 \mathrm{E}-03$ & $4,64 \mathrm{E}-03$ \\
\hline
\end{tabular}

The corresponding figures are below.

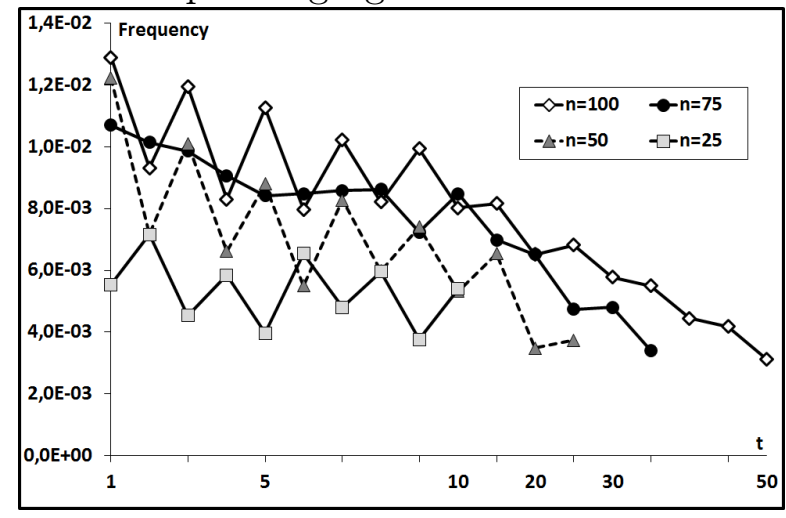

Fig. 1 Frequencies of violation of $R A$ under $I A C$ for $F_{1}$ and $n \in\{25,50,75,100\}$

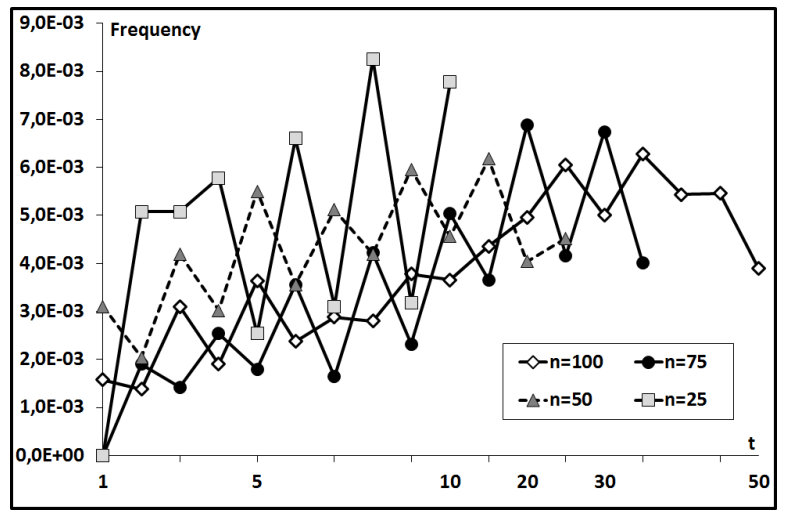

Fig. 2 Frequencies of violation of $R A$ under $I A C$ for $F_{2}$ and $n \in\{25,50,75,100\}$ 


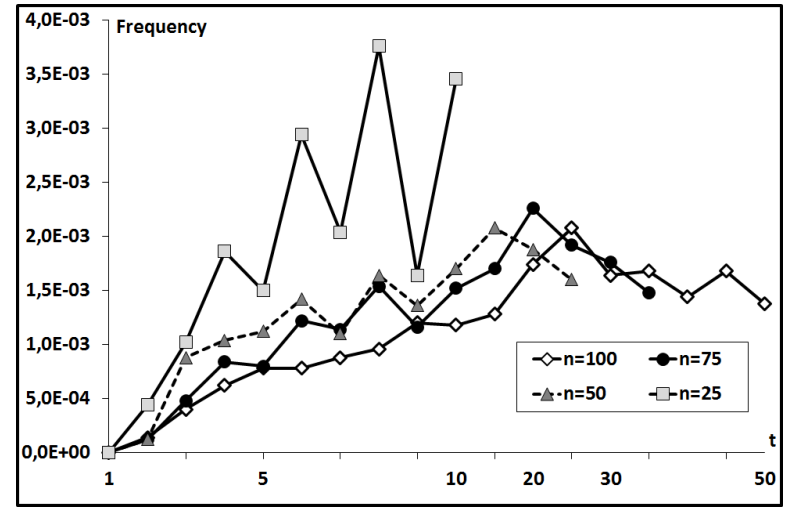

Fig. 3 Frequencies of violation of RA under IAC for $F_{3}-F_{4}-F_{5}-F_{6}$ and $n \in\{25,50,75,100\}$

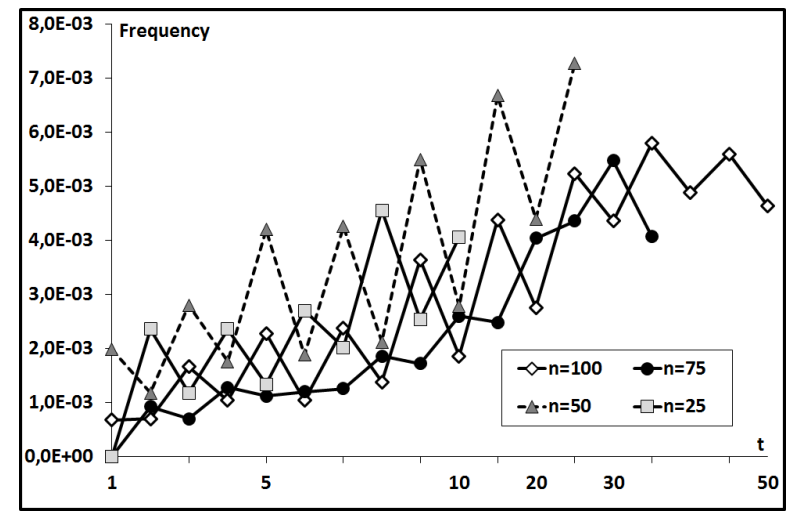

Fig. 5 Frequencies of violation of $R A$ under $I A C$ for $F_{9}$ and $n \in\{25,50,75,100\}$

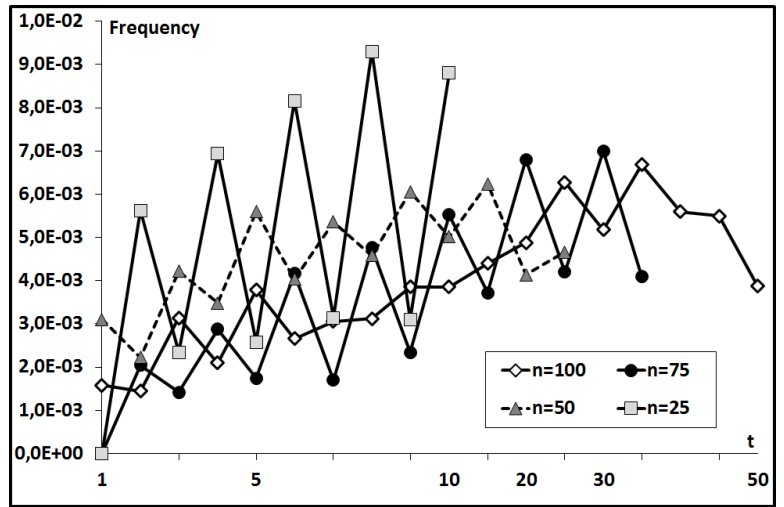

Fig. 4 Frequencies of violation of $R A$ under IAC for $F_{7}-F_{8}$ and $n \in\{25,50,75,100\}$

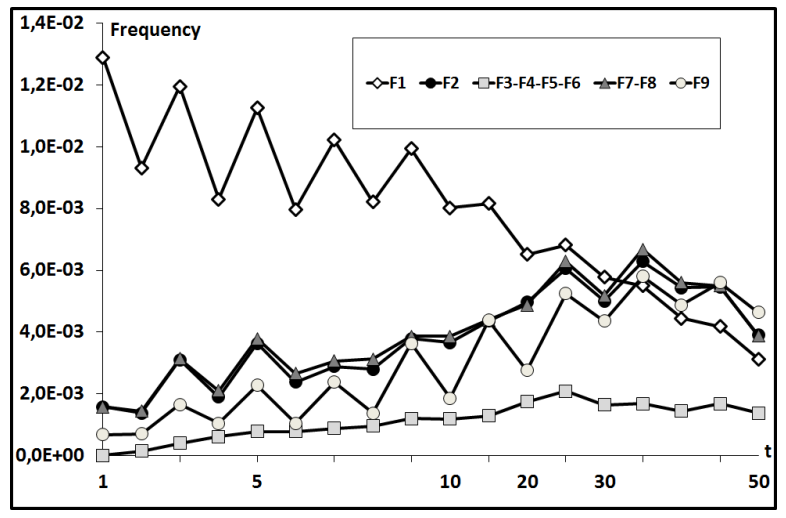

Fig. 6 A comparison of the nine rules under IAC

for $n=100$

These results illustrate the following facts:

(i) for all rules under study, it appears that for any given value of $n$, and for all values of $t$, frequencies of violation of $R A$ are relatively small (generally smaller than 1\%); (ii) although all frequencies are rather small, they are clearly smaller for $F_{3}-F_{4}-F_{5}-F_{6}$ than for $F_{2}, F_{7}-F_{8}$ and $F_{9}$; and for these three families of rules the results are relatively close, as illustrated in Fig. 6 ; (iii) it must also be noticed that $F_{1}$ appears as the worst procedure, especially when the size of one of the two constituencies is relatively greater than the size of the other one; (iv) except for $F_{1}$, for any fixed value of $n$, frequencies slightly increase when $t$ rises (fluctuations are due to even or odd values of $t$ ) as illustrated in Figs. 2, 3, 4, 5; (v) for any given value of $t$, frequencies for $F_{3}-F_{4}-F_{5}-F_{6}$ decrease when $n$ rises, whereas this is not clear for $F_{2}, F_{7}-F_{8}$ and $F_{9}$; (vi) it follows that frequencies are higher as both constituencies tend to have the same size for all the rules with the exception of $F_{1}$; (vii) a contrario, frequencies for $F_{1}$ are relatively smaller with equal size constituencies. Indeed as observed in Fig. 1, for any fixed $n$, frequencies decrease when the value of $t$ rises, and for any given value of $t$, frequencies increase when the value of $n$ rises.

To summarize, we have shown that for $F_{j}, j=2,3,4,5,6,7,8,9$, the frequency of occurrence is maximal when both group tend to have the same size, whereas for $F_{1}$ we have the opposite phenomenon.

Now, one natural question is about the limit frequencies as $n$ gets larger. 


\subsubsection{Exact limiting results}

We now focus on large electorates - and indeed on infinite electorates, that is on cases where the total number of voters in both constituencies tends to infinity. Let $R A\left(F_{j}, \infty\right)$ be the vulnerability of the voting rule $F_{j}$ as the total number of voters tends to infinity and $R A\left(F_{j}, \alpha, \infty\right)$ be the vulnerability of the voting rule $F_{j}$ as the total number of voters tends to infinity assuming that the proportion of voters in the first constituency is exactly $\alpha$, with $\left.\alpha \in] 0, \frac{1}{2}\right]$. We provide closed-form formulae giving this likelihood for Copeland, Schwartz, Fishburn and the Amendment rules. For the other rules similar results require very involved computations. ${ }^{4}$

We then can state the following results.

Proposition 13. Let the Copeland rule be the voting rule. Then

i) $R A\left(F_{2}, \infty\right)=\frac{31}{6144} \approx 2.528 \times 10^{-3}$

ii) $R A\left(F_{2}, \alpha, \infty\right)$

$$
\begin{aligned}
= & -\frac{1}{258048} \frac{\alpha\left(28083 \alpha^{4}-70160 \alpha^{3}+68490 \alpha^{2}-30960 \alpha+5460\right)}{(\alpha-1)^{5}} \text { if } 0 \leq \alpha \leq \frac{1}{3} \\
= & \frac{\left(\begin{array}{l}
30966 \alpha^{10}-126670 \alpha^{9}+226755 \alpha^{8}-231480 \alpha^{7}+147630 \alpha^{6} \\
-61236 \alpha^{5}+17010 \alpha^{4}-3240 \alpha^{3}+405 \alpha^{2}-30 \alpha+1
\end{array}\right)}{258048 \alpha^{5}(\alpha-1)^{5}} \text { if } \frac{1}{3} \leq \alpha \leq \frac{1}{2}
\end{aligned}
$$

After computations it appears that $R A\left(F_{2}, \alpha, \infty\right)=R A\left(F_{7}, \alpha, \infty\right)=R A\left(F_{8}, \alpha, \infty\right)=R A\left(F_{9}, \alpha, \infty\right)$ and $R A\left(F_{2}, \infty\right)=R A\left(F_{7}, \infty\right)=R A\left(F_{8}, \infty\right)=R A\left(F_{9}, \infty\right)$. This result is consistent with the previous simulation observations.

For some values of $\alpha$, we have the following results in Table 3 .

Table 3 (IAC 3) Frequencies of violation of $R A$ for large electorates

\begin{tabular}{cccccccc}
\hline$\alpha$ & $F_{2}-F_{7}-F_{8}-F_{9}$ & $\alpha$ & $F_{2}-F_{7}-F_{8}-F_{9}$ & $\alpha$ & $F_{2}-F_{7}-F_{8}-F_{9}$ & $\alpha$ & $F_{2}-F_{7}-F_{8}-F_{9}$ \\
\hline 0,025 & $5,20 \mathrm{E}-04$ & 0,15 & $2,80 \mathrm{E}-03$ & 0,275 & $4,40 \mathrm{E}-03$ & 0,4 & $5,13 \mathrm{E}-03$ \\
0,05 & $1,02 \mathrm{E}-03$ & 0,175 & $3,18 \mathrm{E}-03$ & 0,3 & $4,63 \mathrm{E}-03$ & 0,425 & $5,24 \mathrm{E}-03$ \\
0,075 & $1,50 \mathrm{E}-03$ & 0,2 & $3,53 \mathrm{E}-03$ & 0,325 & $4,83 \mathrm{E}-03$ & 0,45 & $5,33 \mathrm{E}-03$ \\
0,1 & $1,96-03$ & 0,225 & $3,85 \mathrm{E}-03$ & 0,35 & $4,83 \mathrm{E}-03$ & 0,475 & $5,39 \mathrm{E}-03$ \\
0,125 & $2,39 \mathrm{E}-03$ & 0,25 & $4,14 \mathrm{E}-03$ & 0,375 & $5,00 \mathrm{E}-03$ & 0,5 & $5,42 \mathrm{E}-03$ \\
\hline
\end{tabular}

Graphically, we have the following results in Fig.7.

\footnotetext{
${ }^{4}$ The main difficulty encountered is the evaluation of an 11-dimensional volume over a parameterized polytope.
} 


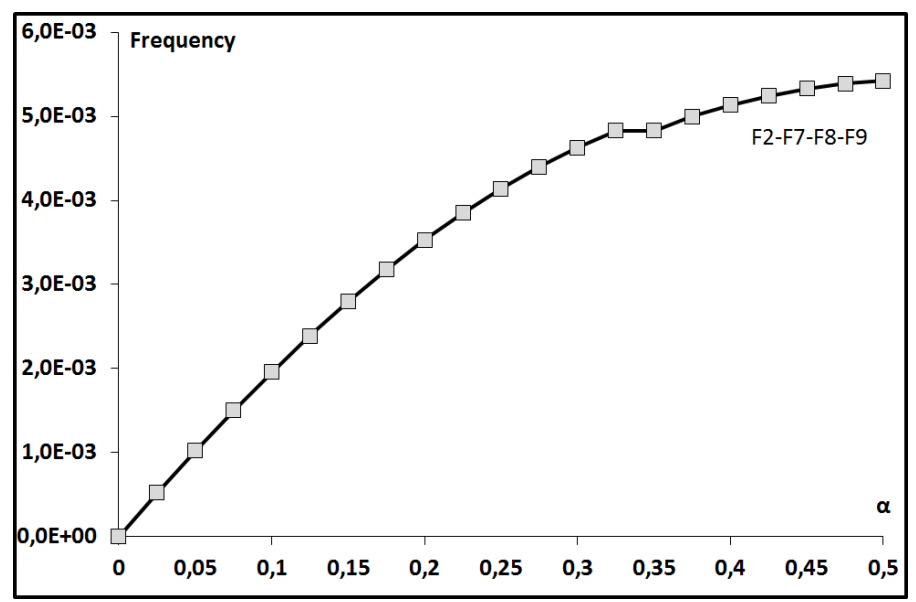

Fig. 7 Frequencies of violation of $R A$ under IAC for

$F_{2}-F_{7}-F_{8}-F_{9}$ with large electorate

As seen above, it appears that: (i) in general, cases of violations are rather rare, (ii) highest frequencies are reached for electorates with equal size constituencies.

\subsection{Impartial culture}

As for $I A C$ above, we consider $n=\{25,50,75,100\}$ and let $t$ change from 1 to $\frac{n}{2}$. Again, the Monte Carlo technique leads to the results provided in Tables 4 and 5 below:

Table 4 (IC 1) Frequencies of violation of $R A$ for Condorcet procedures with $n=25$ and $n=50$

\begin{tabular}{|c|c|c|c|c|c|c|c|c|c|c|}
\hline \multirow[t]{2}{*}{$t$} & \multicolumn{5}{|l|}{$n=25$} & \multicolumn{5}{|l|}{$n=50$} \\
\hline & $F_{1}$ & $F_{2}$ & $F_{3}, F_{4}, F_{5}, F_{6}$ & $F_{7}, F_{8}$ & $F_{9}$ & $F_{1}$ & $F_{2}$ & $F_{3}, F_{4}, F_{5}, F_{6}$ & $F_{7}, F_{8}$ & $F_{9}$ \\
\hline 1 & $3,76 \mathrm{E}-03$ & $0,00 \mathrm{E}+00$ & $0,00 \mathrm{E}+00$ & $0,00 \mathrm{E}+00$ & $0,00 \mathrm{E}+00$ & $1,28 \mathrm{E}-02$ & $7,12 \mathrm{E}-03$ & $0,00 \mathrm{E}+00$ & $7,12 \mathrm{E}-03$ & $6,02 \mathrm{E}-03$ \\
\hline 2 & $1,04 \mathrm{E}-03$ & $6,12 \mathrm{E}-03$ & $6,00 \mathrm{E}-03$ & 1,07E-02 & $6,80 \mathrm{E}-04$ & $5,70 \mathrm{E}-03$ & $3,04 \mathrm{E}-03$ & $2,42 \mathrm{E}-03$ & $4,84 \mathrm{E}-03$ & $6,20 \mathrm{E}-04$ \\
\hline 3 & $3,44 \mathrm{E}-03$ & $9,80 \mathrm{E}-04$ & $9,00 \mathrm{E}-04$ & $9,80 \mathrm{E}-04$ & $4,40 \mathrm{E}-04$ & $1,02 \mathrm{E}-02$ & $7,82 \mathrm{E}-03$ & $1,02 \mathrm{E}-03$ & $7,86 \mathrm{E}-03$ & $8,62 \mathrm{E}-03$ \\
\hline 4 & $1,01 \mathrm{E}-02$ & $7,60 \mathrm{E}-03$ & $6,32 \mathrm{E}-03$ & $1,24 \mathrm{E}-02$ & $2,38 \mathrm{E}-03$ & $5,74 \mathrm{E}-03$ & $3,46 \mathrm{E}-03$ & $2,62 \mathrm{E}-03$ & $4,82 \mathrm{E}-03$ & $1,80 \mathrm{E}-03$ \\
\hline 5 & $3,12 \mathrm{E}-03$ & $1,42 \mathrm{E}-03$ & $1,36 \mathrm{E}-03$ & $1,56 \mathrm{E}-03$ & $1,12 \mathrm{E}-03$ & $9,68 \mathrm{E}-03$ & $7,98 \mathrm{E}-03$ & $1,46 \mathrm{E}-03$ & $7,96 \mathrm{E}-03$ & $1,00 \mathrm{E}-02$ \\
\hline 6 & $1,07 \mathrm{E}-02$ & $9,64 \mathrm{E}-03$ & $7,14 \mathrm{E}-03$ & $1,28 \mathrm{E}-02$ & $4,06 \mathrm{E}-03$ & $5,28 \mathrm{E}-03$ & $3,46 \mathrm{E}-03$ & $2,54 \mathrm{E}-03$ & $4,82 \mathrm{E}-03$ & $2,74 \mathrm{E}-03$ \\
\hline 7 & $2,66 \mathrm{E}-03$ & $1,84 \mathrm{E}-03$ & $1,82 \mathrm{E}-03$ & $1,98 \mathrm{E}-03$ & $1,72 \mathrm{E}-03$ & $9,46 \mathrm{E}-03$ & $8,74 \mathrm{E}-03$ & $1,82 \mathrm{E}-03$ & $8,78 \mathrm{E}-03$ & $1,05 \mathrm{E}-02$ \\
\hline 8 & $9,52 \mathrm{E}-03$ & $1,06 \mathrm{E}-02$ & $6,92 \mathrm{E}-03$ & $1,36 \mathrm{E}-02$ & $4,88 \mathrm{E}-03$ & $5,60 \mathrm{E}-03$ & $4,24 \mathrm{E}-03$ & $2,90 \mathrm{E}-03$ & $4,98 \mathrm{E}-03$ & $3,40 \mathrm{E}-03$ \\
\hline 9 & $3,24 \mathrm{E}-03$ & $1,78 \mathrm{E}-03$ & $1,58 \mathrm{E}-03$ & $1,86 \mathrm{E}-03$ & $2,08 \mathrm{E}-03$ & $9,44 \mathrm{E}-03$ & $8,54 \mathrm{E}-03$ & $2,28 \mathrm{E}-03$ & $8,68 \mathrm{E}-03$ & $1,07 \mathrm{E}-02$ \\
\hline 10 & $9,32 \mathrm{E}-03$ & $1,04 \mathrm{E}-02$ & $7,34 \mathrm{E}-03$ & $1,35 \mathrm{E}-02$ & $4,84 \mathrm{E}-03$ & $4,64 \mathrm{E}-03$ & $3,98 \mathrm{E}-03$ & $2,68 \mathrm{E}-03$ & $4,84 \mathrm{E}-03$ & $3,60 \mathrm{E}-03$ \\
\hline 15 & & & & & & $5,44 \mathrm{E}-03$ & $6,70 \mathrm{E}-03$ & $1,82 \mathrm{E}-03$ & $6,44 \mathrm{E}-03$ & $1,15 \mathrm{E}-02$ \\
\hline 20 & & & & & & $4,54 \mathrm{E}-03$ & $3,98 \mathrm{E}-03$ & $2,56 \mathrm{E}-03$ & $4,72 \mathrm{E}-03$ & $5,62 \mathrm{E}-03$ \\
\hline 25 & & & & & & $7,58 \mathrm{E}-03$ & $7,68 \mathrm{E}-03$ & $2,26 \mathrm{E}-03$ & $7,50 \mathrm{E}-03$ & $1,21 \mathrm{E}-02$ \\
\hline
\end{tabular}


Table 5 (IC 2) Frequencies of violation of $R A$ for Condorcet procedure with $n=75$ and $n=100$

\begin{tabular}{|c|c|c|c|c|c|c|c|c|c|c|}
\hline \multirow[t]{2}{*}{$t$} & \multicolumn{5}{|l|}{$n=75$} & \multicolumn{5}{|l|}{$n=100$} \\
\hline & $F_{1}$ & $F_{2}$ & $F_{3}, F_{4}, F_{5}, F_{6}$ & $F_{7}, F_{8}$ & $F_{9}$ & $F_{1}$ & $F_{2}$ & $F_{3}, F_{4}, F_{5}, F_{6}$ & $F_{7}, F_{8}$ & $F_{9}$ \\
\hline 1 & $9,00 \mathrm{E}-03$ & $0,00 \mathrm{E}+00$ & $0,00 \mathrm{E}+00$ & $0,00 \mathrm{E}+00$ & $0,00 \mathrm{E}+00$ & $1,41 \mathrm{E}-02$ & $6,04 \mathrm{E}-03$ & $0,00 \mathrm{E}+00$ & $6,04 \mathrm{E}-03$ & $4,10 \mathrm{E}-03$ \\
\hline 2 & $8,30 \mathrm{E}-03$ & $3,78 \mathrm{E}-03$ & $2,92 \mathrm{E}-03$ & $6,46 \mathrm{E}-03$ & $6,00 \mathrm{E}-04$ & $6,06 \mathrm{E}-03$ & $3,00 \mathrm{E}-03$ & $1,82 \mathrm{E}-03$ & $4,72 \mathrm{E}-03$ & $4,80 \mathrm{E}-04$ \\
\hline 3 & $7,26 \mathrm{E}-03$ & $1,16 \mathrm{E}-03$ & $1,08 \mathrm{E}-03$ & $1,16 \mathrm{E}-03$ & $4,80 \mathrm{E}-04$ & $1,20 \mathrm{E}-02$ & $7,06 \mathrm{E}-03$ & $7,60 \mathrm{E}-04$ & $7,14 \mathrm{E}-03$ & $6,98 \mathrm{E}-03$ \\
\hline 4 & $1,00 \mathrm{E}-02$ & $5,92 \mathrm{E}-03$ & $3,74 \mathrm{E}-03$ & $8,26 \mathrm{E}-03$ & $1,96 \mathrm{E}-03$ & $7,26 \mathrm{E}-03$ & $4,18 \mathrm{E}-03$ & $2,50 \mathrm{E}-03$ & $5,72 \mathrm{E}-03$ & $1,68 \mathrm{E}-03$ \\
\hline 5 & $6,64 \mathrm{E}-03$ & $1,84 \mathrm{E}-03$ & $1,50 \mathrm{E}-03$ & $1,78 \mathrm{E}-03$ & $1,20 \mathrm{E}-03$ & $1,12 \mathrm{E}-02$ & $8,10 \mathrm{E}-03$ & $1,78 \mathrm{E}-03$ & $8,14 \mathrm{E}-03$ & $7,56 \mathrm{E}-03$ \\
\hline 6 & $1,05 \mathrm{E}-02$ & $8,24 \mathrm{E}-03$ & $4,32 \mathrm{E}-03$ & $1,06 \mathrm{E}-02$ & $2,86 \mathrm{E}-03$ & $7,18 \mathrm{E}-03$ & $4,08 \mathrm{E}-03$ & $2,34 \mathrm{E}-03$ & $5,42 \mathrm{E}-03$ & $2,28 \mathrm{E}-03$ \\
\hline 7 & $5,98 \mathrm{E}-03$ & $2,64 \mathrm{E}-03$ & $1,66 \mathrm{E}-03$ & $2,58 \mathrm{E}-03$ & $1,78 \mathrm{E}-03$ & $1,14 \mathrm{E}-02$ & $8,48 \mathrm{E}-03$ & $2,08 \mathrm{E}-03$ & $9,20 \mathrm{E}-03$ & $8,30 \mathrm{E}-03$ \\
\hline 8 & $8,96 \mathrm{E}-03$ & $7,76 \mathrm{E}-03$ & $4,10 \mathrm{E}-03$ & $1,00 \mathrm{E}-02$ & $3,32 \mathrm{E}-03$ & $6,30 \mathrm{E}-03$ & $4,32 \mathrm{E}-03$ & $2,40 \mathrm{E}-03$ & $5,36 \mathrm{E}-03$ & $3,16 \mathrm{E}-03$ \\
\hline 9 & $6,46 \mathrm{E}-03$ & $2,74 \mathrm{E}-03$ & $2,28 \mathrm{E}-03$ & $2,86 \mathrm{E}-03$ & $2,00 \mathrm{E}-03$ & $1,05 \mathrm{E}-02$ & $8,12 \mathrm{E}-03$ & $2,08 \mathrm{E}-03$ & $7,76 \mathrm{E}-03$ & $9,48 \mathrm{E}-03$ \\
\hline 10 & $9,70 \mathrm{E}-03$ & $9,14 \mathrm{E}-03$ & $4,44 \mathrm{E}-03$ & $1,10 \mathrm{E}-02$ & $4,32 \mathrm{E}-03$ & $6,20 \mathrm{E}-03$ & $5,32 \mathrm{E}-03$ & $2,62 \mathrm{E}-03$ & $6,02 \mathrm{E}-03$ & $3,60 \mathrm{E}-03$ \\
\hline 15 & $6,30 \mathrm{E}-03$ & $3,92 \mathrm{E}-03$ & $2,78 \mathrm{E}-03$ & $4,08 \mathrm{E}-03$ & $3,16 \mathrm{E}-03$ & $9,30 \mathrm{E}-03$ & $8,10 \mathrm{E}-03$ & $2,18 \mathrm{E}-03$ & $8,36 \mathrm{E}-03$ & $1,05 \mathrm{E}-02$ \\
\hline 20 & $8,34 \mathrm{E}-03$ & $9,72 \mathrm{E}-03$ & $4,68 \mathrm{E}-03$ & $1,12 \mathrm{E}-02$ & $6,20 \mathrm{E}-03$ & $6,24 \mathrm{E}-03$ & $5,66 \mathrm{E}-03$ & $2,98 \mathrm{E}-03$ & $6,20 \mathrm{E}-03$ & $4,94 \mathrm{E}-03$ \\
\hline 25 & $5,16 \mathrm{E}-03$ & $4,16 \mathrm{E}-03$ & $2,50 \mathrm{E}-03$ & $4,08 \mathrm{E}-03$ & $3,98 \mathrm{E}-03$ & $7,28 \mathrm{E}-03$ & $8,64 \mathrm{E}-03$ & $2,58 \mathrm{E}-03$ & $8,56 \mathrm{E}-03$ & $1,06 \mathrm{E}-02$ \\
\hline 30 & $7,48 \mathrm{E}-03$ & $9,96 \mathrm{E}-03$ & $4,66 \mathrm{E}-03$ & $1,14 \mathrm{E}-02$ & $7,26 \mathrm{E}-03$ & $4,76 \mathrm{E}-03$ & $5,18 \mathrm{E}-03$ & $2,66 \mathrm{E}-03$ & $5,62 \mathrm{E}-03$ & $5,78 \mathrm{E}-03$ \\
\hline 35 & $4,68 \mathrm{E}-03$ & $3,58 \mathrm{E}-03$ & $2,20 \mathrm{E}-03$ & $3,64 \mathrm{E}-03$ & $4,80 \mathrm{E}-03$ & $7,32 \mathrm{E}-03$ & $8,82 \mathrm{E}-03$ & $2,36 \mathrm{E}-03$ & $8,80 \mathrm{E}-03$ & $1,11 \mathrm{E}-02$ \\
\hline 40 & & & & & & $4,92 \mathrm{E}-03$ & $5,40 \mathrm{E}-03$ & $2,86 \mathrm{E}-03$ & $6,00 \mathrm{E}-03$ & $5,86 \mathrm{E}-03$ \\
\hline 45 & & & & & & $6,74 \mathrm{E}-03$ & $7,60 \mathrm{E}-03$ & $2,40 \mathrm{E}-03$ & $7,80 \mathrm{E}-03$ & $1,07 \mathrm{E}-02$ \\
\hline 50 & & & & & & $4,92 \mathrm{E}-03$ & $5,40 \mathrm{E}-03$ & $2,86 \mathrm{E}-03$ & $6,00 \mathrm{E}-03$ & $5,86 \mathrm{E}-03$ \\
\hline
\end{tabular}

The corresponding figures are below.

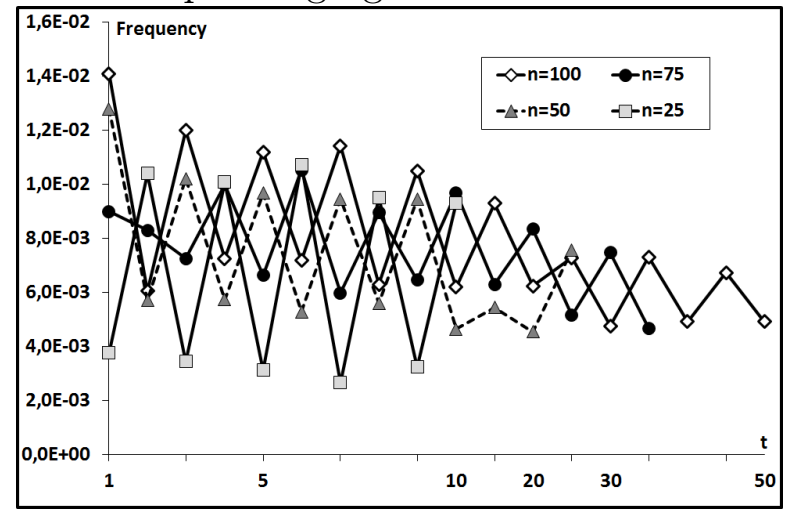

Fig. 8 Frequencies of violation of $R A$ under $I C$ for $F_{1}$ and $n \in\{25,50,75,100\}$

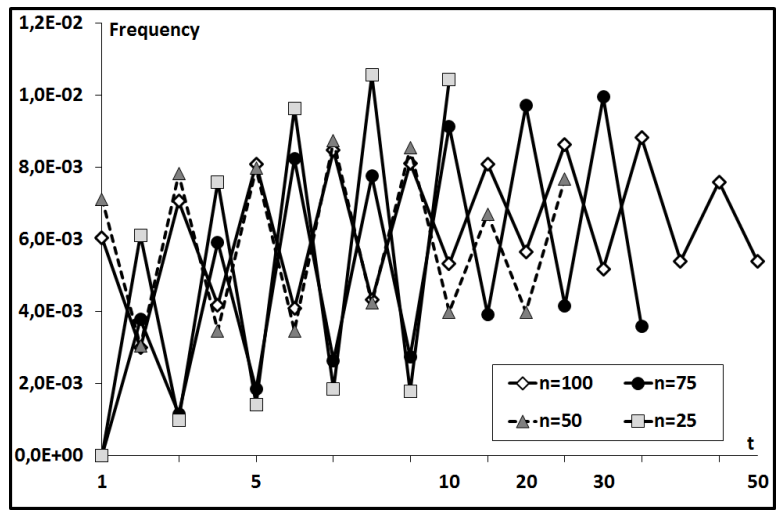

Fig. 9 Frequencies of violation of $R A$ under $I C$ for $F_{2}$ and $n \in\{25,50,75,100\}$ 


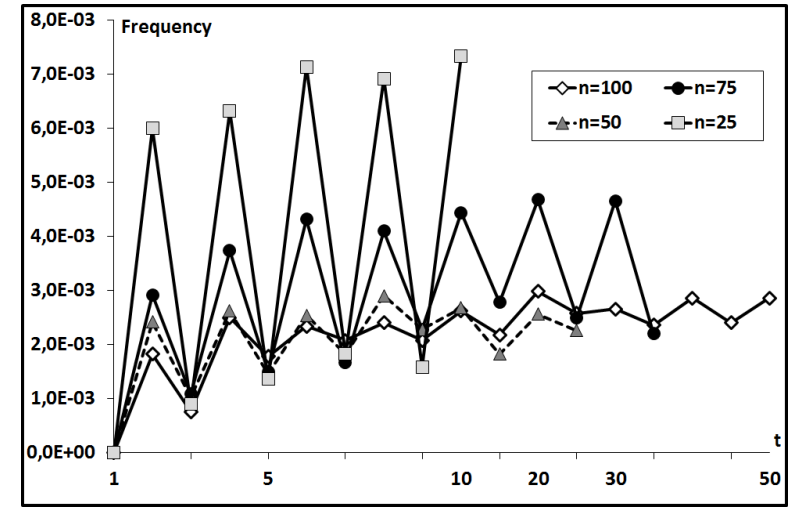

Fig. 10 Frequencies of violation of $R A$ under $I C$ for $F_{3}-F_{4}-F_{5}-F_{6}$ and $n \in\{25,50,75,100\}$

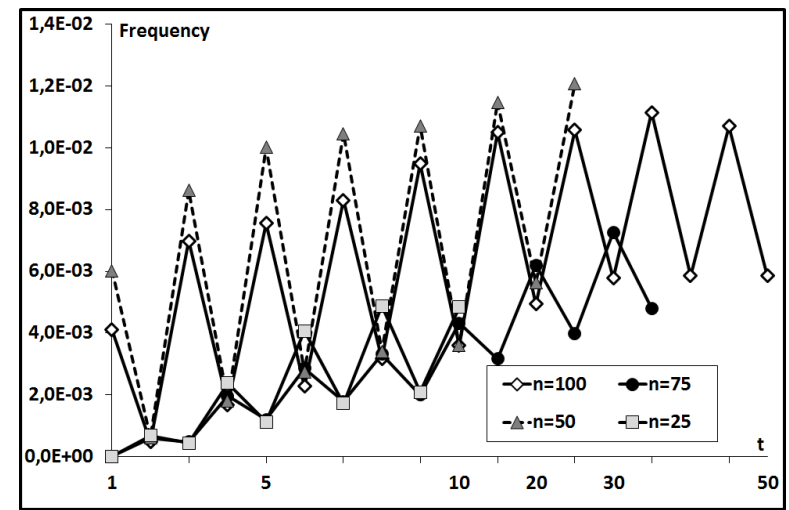

Fig. 12 Frequencies of violation of $R A$ under $I C$ for $F_{9}$ and $n \in\{25,50,75,100\}$

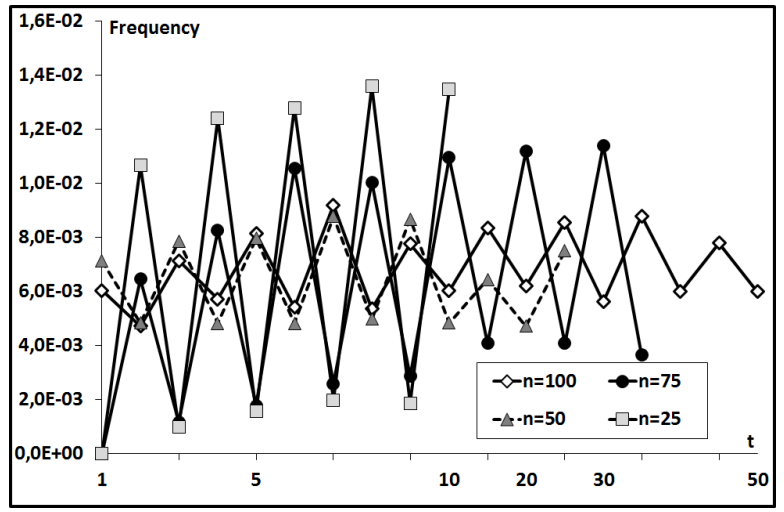

Fig. 11 Frequencies of violation of $R A$ under IC for $F_{7}-F_{8}$ and $n \in\{25,50,75,100\}$

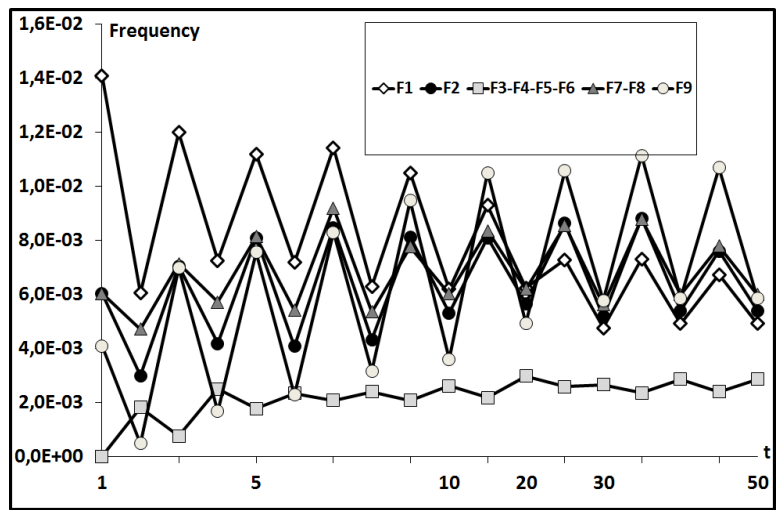

Fig. 13 A comparison of the Condorcet rules under IC for $n=100$

Once again, it can be observed from Figs. 9, 10, 11 and 12 that frequencies of $F_{j}, j=$ $2,3,4,5,6,7,8,9$ are higher as both constituencies tend to have the same size. Moreover, like Fig. 1 above, Fig. 8 shows that $F_{1}$ is more sensitive to the violation of $R A$ with unequal size constituencies. It also appears that the performance of $F_{2}, F_{7}-F_{8}$ and $F_{9}$ are again very close, whereas frequencies of occurence are the smallest for $F_{3}-F_{4}-F_{5}-F_{6}$ and the highest for $F_{1}$.

Besides, it appears that the occurrences of paradoxes are higher under IC than under IAC, which is very common in voting theory (see Gehrlein 2006, chap. 5).

\section{Conclusion}

The goal of this paper was to compare nine Condorcet procedures through the study of their sensitivity to $R A$. In order to do that, we were first concerned with the number of voters at which violations of the axiom occur. It appears that this is the case roughly as soon as the number of voters is equal to 7. Secondly, we provide frequencies of these occurrences. Most of these latter results are based on computer simulations - under two probabilistic classical hypotheses - but some other are obtained with the analytical Fishburn-Gehrlein technique. Results are given for the nine Condorcet procedures. Our results show how these frequencies change according to changes in the values of the total number of voters, and the size of any one of the two constituencies. 
Further, it appears that for all these rules: (i) in general, cases of violations of $R A$ are rather rare, (ii) although all frequencies are small, they are smaller for Dodgson's rule, Young's rule, Condorcet's rule and Kemeny's rule, and (iii) frequencies decrease for electorates with clearly uneven constituencies, with the exception of Black's rule. The main question motivating this study was whether one should be unduly worried about the theoretical possibility of violation of $R A$. The negative answer to this question is the main message of our analysis. Indeed, although all these rules violate $R A$, the frequencies of violation are very rare, as it is the case with sequential positional rules (see Courtin et al. 2010).

Finally, we have observed that in the special case of three alternatives, Dodgson's rule, Young's rule, Condorcet's rule and Kemeny's rule always select the same winner whatever the profile. The same conclusion holds for Schwartz's rule and Fishburn's rule.

\section{References}

[1] Berg S, Lepelley D (1993) Note sur le calcul de la probabilité des paradoxes du vote. Math Informat Sci Hum 120:33-48

[2] Black D (1958) The theory of committees and elections. Cambridge University Press, Cambridge

[3] Copeland AH (1951) A "reasonable" social welfae function. Mimeographed, University of Michigan Seminar on Applications of Mathematics to the Social Science

[4] Courtin S, Mbih B, Moyouwou I, Senné T (2010) The reinforcement axiom under sequential positional rules. Soc Choice Wel 35:473-500

[5] Dodgson CL (1876) A method of taking votes on more than two issues. Clarendon Press, Oxford

[6] Farquharson R (1969) Theory of voting. Yale University Press, New Haven

[7] Fishburn PC (1970) Intransitive indifference with unequal indifference intervals. J Math Psychology 7:144-149

[8] Fishburn PC (1977) Condorcet social choice functions. SIAM J Appli Math 33:469-489

[9] Fishburn PC, Gehrlein WV (1976) Condorcet's paradox and anonymous preference profiles. Public Choice 26:1-18

[10] Gehrlein WV (2006) Condorcet's Paradox. Springer Publishing, Berlin

[11] Kelly, JS (1993) Almost all social choice rules are highly manipulable, but a few aren't. Soc Choice Welf 2:161-175

[12] Kemeny J (1959) Mathematics without numbers. Daedalus 88:577-591

[13] Lepelley D, Louichi A, Smaoui H (2008) On Ehrhart polynomials and probability calculations in voting theory. Soc Choice Wel 30:363-383

[14] Levenglick A (1975) Fair and reasonable election systems. Behavioral Sci 20:34-46 
[15] Moulin H (1988) Axioms of cooperative decision making. Cambridge University Press, Cambridge

[16] Nitzan S (1985) The vulnerability of point voting schemes to preference variation and strategic manipulation. Public Choice 47:349-370

[17] Nurmi H (1987) Comparing voting systems. D.Reidel, Dordrecht

[18] Nurmi H (1999) Voting paradoxes and how to deal with them. Springer-Verlag, BerlinHeidelberg-New York

[19] Nurmi H (2002) Voting Procedures Under Uncertainty. Springer-Verlag, Berlin-HeidelbergNew York

[20] Rasch BE (1995) Parliamentary voting rules. Parliaments and majority rule in western Europe. H. Döring, Frankfurt

[21] Reggenwetter M, Grofman B, Marley AAJ, Tselin IM (2006) Behavioral social choice. Cambridge University Press, Cambridge

[22] Saari DG. (2006) Which is better: the Condorcet or Borda winner? Soc Choice Wel 26:107-130

[23] Schwartz T (1972) Rationality and the myth of the maximum. Noûs 6:97-117

[24] Smith JH (1973) Aggregation of preferences with variable electorate. Econometrica 41:10271041

[25] Young HP (1974) An axiomatization of Borda's rule. J Econ Theory 9:43-52

[26] Young HP (1975a) Social choice scoring functions. SIAM J Appli Math 28:824-838

[27] Young HP (1975b) Extending Condorcet' rule. Mimeographed, The City University of New York 